\title{
A Political Economy Model of Congressional Careers*
}

\author{
Daniel Diermeier \\ MEDS, Kellogg School of Management, Northwestern University \\ Michael Keane \\ Department of Economics, Yale University \\ Antonio Merlo \\ Department of Economics, University of Pennsylvania and CEPR
}

Revised, March 2004

\begin{abstract}
Theories in political economy depend critically on assumptions about motivations of politicians. Our analysis starts from the premise that politicians, like other economic agents, are rational individuals who make career decisions by comparing the expected returns of alternative choices. The main goal of the paper is to quantify the returns to a career in the United States Congress. To achieve this goal we specify a dynamic model of career decisions of a member of Congress and we estimate this model using a newly collected data set. Given estimates of the structural model, we assess reelection probabilities for members of Congress, estimate the effect of congressional experience on private and public sector wages, and quantify the value of a congressional seat. Moreover, we use the estimated model to assess how an increase in the congressional wage or the imposition of term limits would affect the career decisions of politicians and the returns to a career in Congress.
\end{abstract}

ADDRESS FOR CORRESPONDENCE: Antonio Merlo, Department of Economics, University of Pennsylvania, 3718 Locust Walk, Philadelphia, PA 19104. E-mail: merloa@econ.upenn.edu

* We would like to thank Tim Besley, two anonymous referees, Nolan McCarty, Tim Groseclose, John Rust, Jim Snyder, Ken Wolpin, and seminar and conference participants at many institutions for their helpful comments and suggestions. We would also like to thank David Brady, Tim Groseclose, Gary Jacobson, Rod Kiewitt, David Mayhew, Doug Rivers and Lanche Zheng for giving us access to their data. Financial support from National Science Foundation grant SBR-9730483 is gratefully acknowledged. Sameer Agrawal, David Choate, David Fang, Nicole Foo, Cary Frydman, Stuart Guerera, Elizabeth Holden, Na Yeon Kim, Roger Loh, Kristen Lueking and especially Andrew Ching provided excellent research assistance. 


\section{Introduction}

Understanding the goals of elected office holders is of fundamental importance in political economy. Since the appearance of Anthony Downs' (1957) seminal contribution, many theories of representative democracy have assumed that politicians care only about winning elections. ${ }^{1}$ While useful in modeling many political decision processes, assuming that politicians are solely interested in the goal of reelection makes them seem like odd economic agents. In fact, reelection may be better understood as an (intermediate) objective to realize other goals, like monetary income, the perks of a powerful public office, or the desire to implement certain policies. ${ }^{2}$ This suggests an exploration of politicians' motivations in the context of their political careers, and raises the fundamental question: What are the returns to an individual from a career in politics?

A shift from a reelection focus to the study of political careers may have important policyrelevant implications. Consider, for example, the case of term limits. Empirical work on U.S. congressional elections has generated concerns that very high incumbent reelection rates, and the prevalence of large victory margins, may have eroded public accountability of elected officials. ${ }^{3}$ These concerns have led several interest groups to advocate the imposition of term limits as a possible remedy. ${ }^{4}$ This focus on electoral success, however, may underestimate the electoral risk of incumbents, since particularly vulnerable incumbents may exit in anticipation of electoral defeat. Furthermore, by altering the incentives faced by politicians, term limits are likely to affect their career decisions and may therefore have important consequences for the composition of Congress.

Our analysis starts from the premise that politicians, like other economic agents, are rational individuals who make career decisions by comparing the expected returns of alternative choices. The main goal of the paper is to quantify the returns to a career in the United States Congress. To achieve this goal, we specify a dynamic model of career decisions of a member of Congress, and estimate this model using a newly collected data set that contains detailed information on all members of Congress in the post-war period. A novel feature of the data is that it incorporates information about post-congressional employment and salaries when members exit Congress. This crucial piece of information allows us to estimate the returns to congressional experience in postcongressional employment, which may be an important part of the return to congressional careers.

\footnotetext{
${ }^{1}$ E.g., Downs' own theory of electoral competition, and Mayhew's (1974a) theory of internal organization of Congress.

${ }^{2}$ For models where politicians are only policy motivated see, e.g., Alesina (1988) and Wittman (1977). See also the related work on citizen candidates by Besley and Coate (1997) and Osborne and Slivinsky (1996).

${ }^{3}$ See, e.g., Bauer and Hibbing (1989), Jacobson (1987), and Mayhew (1974b).

${ }^{4}$ See, e.g., Benjamin and Malbin (1992).
} 
Our framework enables us to sort out the relative importance of two key factors that may induce people to pursue a political career: the utility politicians derive from being in office and the monetary returns to a career in Congress. Using data on important legislative achievements by members of Congress, we relate part of the non-pecuniary rewards from serving in Congress to the desire for political accomplishments. Using our model, we also assess the selection bias in estimates of election probabilities based only on politicians who choose to run, investigate the extent to which politicians' career choices respond to wage incentives, and evaluate the effects of term limits on the value of a congressional seat and on the career decisions of politicians.

The study of congressional careers has a long tradition in American politics (see, e.g., Schlesinger (1966) and Hibbing (1991)). Recently, several authors have studied the determinants of representatives' choices among three basic career options: (i) run for reelection; (ii) run for higher office (e.g., run for Senate in the case of House members), and (iii) retire (see, e.g., Groseclose and Krehbiel (1994), Groseclose and Milyo (1999), Hall and van Houweling (1995), and Kiewiet and Zeng (1993)). Existing studies, however, suffer from four main limitations that we seek to address:

First, prior studies have estimated static choice models that do not take into account the dynamic aspects of politicians' career choices. For example, the decision of a member of Congress to seek reelection is likely to depend not only on current payoffs, which depend, in turn, on the probability of winning today, but also on the option value of holding the seat, which may depend on the probability of winning a bid for higher office in the future. A second, closely related, problem, is that existing studies ignore the career prospects of politicians after they leave Congress (either voluntarily or via losing an election). In deciding whether to run for reelection, a politician may consider how post-congressional wages are influenced by congressional experience. If congressional experience is valuable in the private sector, it may be optimal for politicians to opt out of Congress at particular points in their careers so as to maximize post-congressional payoffs.

A third limitation of existing studies is that they typically ignore the selection bias created by politicians' decisions about whether to run for reelection. ${ }^{5}$ If we ignore the fact that members of Congress may decide whether to run for reelection or higher office based, at least in part, on their probability of success, this may result in biased estimates of the probabilities of winning elections (see, e.g., Heckman (1979)). A fourth, and related, problem is the failure to deal with unobserved heterogeneity. While the importance of taking into account politicians' (unobservable) personal

\footnotetext{
${ }^{5}$ See Groseclose and Krehbiel (1994) for an exception.
} 
characteristics, such as "valence" or "charisma," has been recognized by the theoretical literature (see, e.g., Aragones and Palfrey (2002) and Groseclose (2001)), the empirical literature has net yet incorporated politicians' unobserved heterogeneity into the analysis of their career choices.

In this paper we provide a new, comprehensive framework for the empirical analysis of congressional careers that adresses these four limitations. Specifically, we develop a dynamic optimization model of the career decisions of a member of the U.S. Congress. We extend prior work by explicitly modelling their career opportunities outside Congress. In particular, we assume that when a politician exits from Congress, he/she can choose between two employment options: one in the private sector and one in the public sector. The wage the politician may obtain in each sector depends, among other things, on congressional experience. In addition, we assume that politicians differ with respect to their (unobserved) skills, which, together with other (observed) characteristics, may affect both their probabilities of winning elections and post-congressional payoffs. ${ }^{6}$ We also allow for the possibility that politicians differ with respect to their preferences for holding public office, which may affect their utility from achieving important legislative accomplishments during their congressional tenure and hence their payoffs from serving in Congress.

Our main findings can be summarized as follows. First, congressional experience significantly increases post-congressional wages, both in the private and public sectors. However, the marginal effect of congressional experience on post-congressional wages diminishes quite rapidly with additional experience. Second, the non-pecuniary rewards from being in Congress are rather large (especially in the Senate), suggesting that policy motivations and perks of office play important roles in the career decisions of politicians. In particular, monetary returns alone (that is, wages in Congress and post-congressional payoffs), cannot explain the observed behavior of politicians, and the effect of the congressional wage on their behavior is quite small. Moreover, the payoffs from achieving important legislative accomplishments are quite large (both in the House and in the Senate), although such accomplishments are rare.

Third, politicians' unobserved skill (e.g., valence or charisma), play an important role throughout their congressional careers, as "skilled" politicians have a substantially higher probability of winning elections. However, being a skilled politician does not seem to generate better job-market opportunities outside Congress. Thus, there is evidence of comparative advantage, since the relatively skilled politicians are not relatively productive in the private sector. Fourth, we 
find that the selectivity bias induced by politicians' decisions whether to run for reelection is actually rather modest. Reelection probabilities in the House and Senate are indeed very high, even unconditionally. However, there is substantial selection in terms of who runs for higher office, so that the unconditional probability of a House member winning a bid for higher office is much lower than is suggested by the observed frequency of successful bids.

Finally, we find that the imposition of term limits would substantially increase early voluntary exit from Congress and significantly reduce the value of a congressional seat. Moreover, our analysis indicates that the members of Congress most negatively affected by term limits would be those with better political skills, those who value personal political achievements more, and those who are older.

The rest of the paper is as follows. In Section 2, we present the model. In Section 3, we describe the data. In Section 4, we present our estimation results. In Section 5, we assess the value of a congressional seat. In Section 6, we present the results of two policy experiments on increasing congressional wages and imposing term limits, respectively. We conclude with Section 7.

\section{A Structural Model of Congressional Careers}

We assume that politicians make decisions about running for reelection, running for higher office, and exiting from Congress (either to retirement or another type of work) every two years - the length of a House term. Politicians are forward looking, and realize that current decisions affect the distribution of future payoffs. Thus, they must solve a dynamic optimization problem to determine the current decision that maximizes expected present value of lifetime utility (see, e.g., Eckstein and Wolpin (1989) and Rust (1994)).

We assume that the earliest age at which a person can be elected to Congress is 30 and if a politician lives to age 80 , then he/she must exit Congress at that point. ${ }^{7}$ These assumptions imply that the dynamic optimization problem has (at most) 25 decision periods. Furthermore, it greatly simplifies our analysis to assume that exit from Congress is an absorbing state-that is, the politician cannot return to Congress after leaving, regardless of the age at which he or she exits. ${ }^{8}$

Our model can usefully be decomposed into several parts. These are: (i) post-congressional payoffs, (ii) the decisions of members of Congress, and (iii) probabilities of winning elections, committee assignments and legislative achievements. We now describe these in turn.

\footnotetext{
${ }^{6}$ For example, the ability of politicians to empathize with people may affect their ability to win elections.

${ }^{7}$ Despite some well-publicized exceptions, entering Congress prior to age 30 or staying after age 80 are rare events.

${ }^{8}$ Returning to Congress after an exit is also a rare event (it occurs in less than $5 \%$ of the cases), so we feel this is a reasonable simplification.
} 


\subsection{Post-Congressional Payoffs}

At the end of each two-year period, a politician who is in Congress has the option of exiting. A key feature of our model is that, when a politician exits from Congress (either voluntarily or via electoral defeat), he/she can choose between two post-congressional employment options, or else retire. The employment options are (i) work in a private sector occupation, or (ii) work in a public sector occupation (i.e., enter another political job). ${ }^{9}$

The wages the politician may obtain in the two alternative occupations are determined by age, education, and variables characterizing congressional experience. We specify log wage functions similar in functional form to those in the human capital literature (Mincer (1958)), except for the inclusion of the congressional experience variables. Our wage functions take the form:

$$
\begin{aligned}
\ln W_{i j t}= & \beta_{0 j}+\beta_{1 j} \text { Skill }_{i}+\beta_{2 j} B A_{i}+\beta_{3 j} J D_{i}+\beta_{4 j} A g e_{i t}+\beta_{5 j} A g e_{i t}^{2} \\
& +\beta_{6 j} T H_{i t}+\beta_{7 j} T H_{i t}^{2}+\beta_{8 j} T S_{i t}+\beta_{9 j} T S_{i t}^{2}+\beta_{10 j} C O M_{i t}+\beta_{11 j} V E_{i t}+\varepsilon_{i j t}
\end{aligned}
$$

where $W_{i j t}$ is the wage offered to individual $i$ in occupation $j$ in period $t$, for $j=1,2$, and $t=1, \ldots, 25$.

This specification allows for the possibility that individuals have different unobserved endowments of skills for each occupation (as in Keane and Wolpin (1997)). The variable $S_{k i l l}$ indexes the (unobserved) endowment vectors, and is simply a dummy variable equal to 1 if the (unobserved) type of politician $i$ is "skilled." The case where the dummy variable $S_{k i l l_{i}}=0$ corresponds to the default or "normal" type. The error term $\varepsilon_{i j t}$ represents the purely stochastic component of the wage offer, which is revealed when the politician exits Congress. ${ }^{10}$

Turning to the observables in the wage function, $B A_{i}$ and $J D_{i}$ are dummy variables denoting whether individual $i$ has a bachelor's degree and a law degree, respectively. $T H_{i t}$ and $T S_{i t}$ are the number of prior terms served in the House and Senate, respectively. $C O M_{i t}$ is a dummy variable equal to 1 if, during the prior term in the House, a representative had served on a major House committee. ${ }^{11}$ Political scientists typically define the major House committees as Ways and Means, Appropriations, and Rules (see, e.g., Deering and Smith (1990)). The idea is that service on one of these major committees may augment the human capital one brings to post-congressional

\footnotetext{
${ }^{9}$ By other political jobs we are thinking primarily of appointed positions, such as cabinet posts, bureaucratic positions, etc. We abstract from the fact that a politician might have to run (or be confirmed) for some non-congressional positions.

${ }^{10} \mathrm{We}$ assume that the vector of wage error terms $\varepsilon_{i t}=\left(\varepsilon_{i t}, \varepsilon_{i 2 t}\right)$ has a bivariate normal distribution, $\varepsilon_{i t} \sim N\left(0, A A^{\prime}\right)$, where $A$ is a lower triangular matrix with coefficients $a_{11}, a_{12}$ and $a_{22}$.

${ }^{11}$ Committee membership is less important in the modern Senate (Sinclair (1989)).
} 
employment. For example, being a member of Ways and Means might generate knowledge that would enhance one's value as a lobbyist for companies seeking to obtain tax breaks.

Finally, $V E_{i t}$ is an indicator for whether the politician exited Congress voluntarily rather than via losing a reelection bid. Our rationale for including this variable in the wage function is that the mode of exit may affect the value of the politician in certain types of jobs. But the sign of this effect is a priori ambiguous. Losing an election may reduce the politician's value in jobs where popularity is important. But, on the other hand, exiting Congress voluntarily may signal a desire to "slow down," thus reducing the perceived value of the politician to potential employers.

A third option upon exit is retirement. In this case, the politician may, depending on age and length of service, be eligible to receive pension payments. We describe the congressional pension rules in the Appendix. Here, we just write the pension rule as $P E_{i t}\left(A g e_{i t}, T H_{i t}, T S_{i t}\right)$ to indicate that the pension payment $P E_{i t}$ that individual $i$ will begin to receive if he/she retires at time $t$ depends on his/her age as well as terms in the House and Senate. Then, the payoff in the retirement option is:

$$
P R_{i t}=P E_{i t}\left(A g e_{i t}, T H_{i t}, T S_{i t}\right)+\alpha_{L}+\alpha_{V E} V E_{i t} .
$$

The parameter $\alpha_{L}$ captures the monetized value of leisure, while $\alpha_{V E}$ captures an additional value of leisure for those who exit Congress voluntarily rather than via losing an election. Thus, $\alpha_{V E}>0$ captures the notion that those who exit voluntarily desire to "slow down," so their value of leisure after exiting Congress is relatively high. This enables our model to capture the fact that those who exit voluntarily are much more likely to choose retirement rather than further employment, even conditional on age and other characteristics. To achieve a more compact notation, let $X P_{i t}$ denote the set of state variables relevant for the determination of post-congressional payoffs. We have:

$$
X P_{i t}=\left(S_{k i l l}, B A_{i}, J D_{i}, A g e_{i t}, T H_{i t}, T S_{i t}, C O M_{i t}, V E_{i t}\right) .
$$

Equations (1) and (2) give the per-period payoffs for each of the three post-congressional alternatives at exit. We do not model behavior beyond the first choice that a politician makes after exiting Congress. ${ }^{12}$ Rather, we assume that exogenous death and retirement transition probabilities govern outcomes from that point onward. Specifically, if the politician chooses employment option $j$, for $j=1,2$, then he/she will remain in that alternative until either retirement or death. Once the politician enters retirement he/she stays in that state until death. Let $\pi_{r}(t)$, and $\pi_{d}(t)$ be the retirement and death probability, respectively. These are functions of $t$ since they depend on age at exit from

\footnotetext{
${ }^{12}$ We do this because, in our data, we only observe the first occupation (and first wage) after a politician exits Congress.
} 
Congress. They also vary with age after exit, but it simplifies the exposition to ignore this. ${ }^{13}$ Letting $\delta$ denote the per-period discount factor, the present discounted value of private sector employment can be written as:

$$
P V_{1}\left(W_{i l t}\right)=\frac{W_{i 1 t}+\alpha_{1 C} C O M_{i t}}{1-\delta\left(1-\pi_{d}(t)\right)\left(1-\pi_{r}(t)\right)}+\frac{\delta\left(1-\pi_{d}(t)\right) \pi_{r}(t) P V_{3}\left(P R_{i t}\right)}{1-\delta\left(1-\pi_{d}(t)\right)\left(1-\pi_{r}(t)\right)}
$$

while, for the public sector, we have:

$$
P V_{2}\left(W_{i 2 t}\right)=\frac{W_{i 2 t}+\alpha_{2 W}+\alpha_{2 C} C O M_{i t}}{1-\delta\left(1-\pi_{d}(t)\right)\left(1-\pi_{r}(t)\right)}+\frac{\delta\left(1-\pi_{d}(t)\right) \pi_{r}(t) P V_{3}\left(P R_{i t}\right)}{1-\delta\left(1-\pi_{d}(t)\right)\left(1-\pi_{r}(t)\right)} .
$$

In equation (5), $\alpha_{2 W}$ captures the additional utility from holding another political job. If politicians get non-pecuniary rewards from being in Congress, it seems reasonable to assume they may also get non-pecuniary rewards from other political jobs. $\alpha_{I C}$ and $\alpha_{2 C}$ capture the monetized value of having served on a major House committee, which may generate additional income from speaking engagements, consulting, book contracts, etc.. We allow the value from these activities (which we do not observe) to differ depending on whether the politician's post-congressional occupation is in the private or public sector. Similarly, the present discounted value of the retirement option is:

$$
P V_{3}\left(P R_{i t}\right)=P R_{i t} /\left[1-\delta\left(1-\pi_{d}(t)\right)\right] .
$$

Throughout the model, we assume there is an idiosyncratic (politician specific) taste shock associated with each possible choice a politician can make in any decision period. Thus, regarding post-congressional choices, the values of the three exit options may be written as $V_{j}=P V_{j}+\xi_{j}$ for $j$ $=1,2,3$, where $\xi_{j}$ is the taste shock associated with alternative $j$. Following Rust (1987), we assume all the taste shocks are i.i.d type I extreme value. This assumption allows us to derive simple expressions for the expected maximum value over the whole choice set, $V_{E}\left(X P_{i t}\right)$, as well as for the probabilities a politician would choose any of the three alternatives. ${ }^{14}$

\subsection{Decisions of Members of Congress}

We begin by considering the decisions of a sitting senator. Of course, senators can run for other offices, like president or governor. But such decisions are rather infrequent, and to include them explicitly leads to drastic complications. Thus, we subsume these decisions in the exit option. ${ }^{15}$

\footnotetext{
${ }^{13}$ We construct death probabilities, $\pi_{d}$, from the empirical hazard. However, information on retirement from postcongressional occupations is (for the most part) unavailable. Thus, we assume that the retirement probability $\left(\pi_{r}\right)$ before age 62 is equal to zero, and specify that retirement probabilities after age 62 are a logistic function of age. The coefficients of the retirement probability function are estimated jointly with the other parameters of the model.

${ }^{14}$ For every choice we only need to estimate the standard deviation of the corresponding taste shock. For details on the choice probabilities and the expected value functions, see Diermeier, Keane and Merlo (2004).

${ }^{15}$ That is, if a senator does become a governor, we treat it just like any other post-congressional political job.
} 
Even though a Senate term is six years, we assume that senators make decisions every two years, since early exit by senators is not uncommon in the data. The set of options a senator faces depends on whether his/her seat is up for election in a given period. Define a state variable $S T$ ("Senate term") that is equal to 1, 2 or 3 as the senator has served 2, 4 or the full 6 years of his/her term. If $S T=1,2$ then the senator has two options: to continue sitting in the Senate or exit Congress. If $S T=3$ then the senator has to decide whether to run for reelection or exit Congress.

Denote by $X S_{i t}$ the set of state variables relevant to the decisions of senators. We have:

$$
X S_{i t}=\left(X P_{i t}, S O S_{i t}, S O W_{t}, \text { Party }_{i}, \text { Achieve }_{i}, \text { Scandal }_{i t}, S T_{i t}, \text { Cohort }_{i}\right) .
$$

Obviously this includes $X P_{i t}$, the set of state variables that determine the distribution of postcongressional payoffs should the politician exit the Senate, which we defined in (3). The state vector also contains measures of the political climate, which influence the senator's re-election chances, denoted $S O S_{i t}$ ("state-of-the-State") and $S O W_{t}$ ("state-of-the-world"). These indicate, respectively, whether conditions in the senator's home State and aggregate conditions favor election of a Democrat or a Republican or are neutral. We assume that the senator knows the state of his/her State as well as the state of the world prior to making the decision on whether to retire, run for reelection or stay in the Senate. We describe the construction of these variables in the Appendix. ${ }^{16}$

Cleary the variable Party $_{i}$, which indicates whether a politician is a Democrat or Republican, is also relevant, since, for example, its interaction with $S O S_{i t}$ and $S O W_{t}$ affects a politician's electoral chances. We assume political party is a fixed characteristic of a politician. ${ }^{17}$

We allow politicians to differ with respect to their (unobserved) political skills, summarized by the variable $S k i l l_{i}$, which is contained in $X P_{i t}$. We also allow for the possibility that politicians have different unobserved preferences for holding office, which affect the utility they derive from important legislative accomplishments. The variable Achieve $_{i}$ indexes the (unobserved) preferencetype of a politician and is simply a dummy variable equal to 1 if the politician is an "achiever" (i.e., he/she values personal legislative achievements). As with the variable Skill, the case where Achieve $_{i}=0$ corresponds to the default or "normal" type. Hence, since there are two possible skilltypes and two possible preference-types, our analysis admits four different unobserved types of politicians.

\footnotetext{
${ }^{16}$ The state variables $S O S$ and $S O W$ are assumed to evolve over time according to two (independent) Markov processes with transition probabilities $P\left(S O S_{i, t+1} \mid S O S_{i t}\right)$ and $P\left(S O W_{t+1} \mid S O W_{t}\right)$, respectively. We estimate these probabilities in an unrestricted way from the empirical transition frequencies, and use those values in estimation.
} 
In our empirical work, we define "important legislative accomplishments" to include such things as, e.g., sponsoring a major piece of legislature or casting the decisive vote on an important policy issue. Our measure is based on Mayhew (2000) - see the Appendix for details. Our assumption that there exists an "achiever" type is motivated by the empirical observation that important legislative accomplishments are only attained by a relatively small subset of members of Congress, and that these politicians in turn, often have multiple achievements.

Finally, Scandal ${ }_{i t}$ in (7) is an indicator for being involved in a scandal at time $t$. Obviously, this is relevant to a senator's electoral chances, and may affect his/her decision whether to run. And Cohort $_{i}$ is a variable indicating whether a politician entered Congress in 1947-1965, 1967-1975 or 1977-1993. We use this variable to capture changes in congressional wages over time. ${ }^{18}$

Now consider the decision of a senator when $S T=1$. In this case, the senator's seat is not up for election, so the choice is simply to stay in office or exit. If the senator decides to stay in office, then he/she receives the per-period payoff from sitting in the Senate, which includes the possibility of an important legislative accomplishment in the current session of Congress. Denote by $V_{S}\left(X S_{i t}, s\right)$ the value of choosing the Senate option given the relevant state variables $\left(X S_{i t}, s\right)$, where the second element of the state vector indicates that the politician is already a sitting senator. We have:

$$
V_{S}\left(X S_{i t}, s\right)=W_{S}(t)+\alpha_{S}+\text { Achieve }_{i} p_{A S}\left(X S_{i t}\right) \alpha_{A S}+\mu_{1 S i t}+\delta\left(1-\pi_{d}(t)\right) E V\left(X S_{i, t+1}, s\right) .
$$

The first four terms in (8) capture the immediate payoff from staying in the Senate at time $t$. $W_{S}(t)$ is the wage the senator receives, and $\alpha_{S}$ captures the monetized value of the per-period nonpecuniary rewards from being in the Senate. While all senators receive these rewards, those of the type who value personal legislative achievements (i.e., Achieve $_{i}=1$ ) may also receive additional utility contingent on an important legislative accomplishment. We let $p_{A S}\left(X S_{i t}\right)$ denote the probability of a political achievement by a senator, while $\alpha_{A S}$ is the monetized value of the utility

\footnotetext{
${ }^{17}$ There are instances of politicians changing parties while in Congress over the sample period, but to include the possibility of changing party would substantially complicate our model, and such instances are sufficiently rare (they occur in less than half of a percent of the cases), that we feel it is a reasonable approximation to ignore them.

${ }^{18}$ Wage paths were very similar for members within each entering cohort defined here, regardless of entry year. Thus, we constructed cohort specific wage paths using time-specific averages across the cohort members. If we let each entering class be its own cohort (i.e., have its own wage path), it drastically expands the state space, and increases computational time. This cost did not appear justified given the limited variation of wages within cohorts.
} 
the achievement generates. ${ }^{19}$ The term $\mu_{\text {ISit }}$ is a stochastic component to $i$ 's utility from being in the Senate at time $t$, which may capture random fluctuations in the non-pecuniary rewards over time. ${ }^{20}$

The last term in (8) captures the future component of the value from staying in the Senate. This is equal to the discount factor, $\delta$, times the probability of survival to the next decision period, $\left(1-\pi_{d}(t)\right)$, times the expected value of the state the politician will arrive at in period $t+1$ given survival, $E V\left(X S_{i, t+1}, s\right)$. This is the expected maximum of the value of staying in the Senate, $V_{S}\left(X S_{i, t+1}, s\right)$, and the value of exit, $V_{E}\left(X P_{i, t+1}\right)$, in period $t+1$. The expectation is taken over the time $t^{t+1}$ realizations of the variables $S O S, S O W$ and $\mu_{1 S i t+1}$, which affect the value of these options at $t+1$.

Consider now the senator's decision when $S T=3 .{ }^{21}$ At that point the senator's seat is up for election, and he/she can run for reelection or leave Congress. If the senator runs, the probability of winning is $p_{s}\left(X S_{i t}\right) .{ }^{22}$ Hence, the value of running for reelection to the Senate is given by:

$$
V_{R S}\left(X S_{i t}, s\right)=p_{S}\left(X S_{i t}\right) E V_{S}\left(X S_{i t}, s\right)+\left(1-p_{S}\left(X S_{i t}\right)\right) V_{E}\left(X P_{i t}^{*}\right)+\left(\alpha_{R S}+\mu_{R S i t}\right)
$$

which is equal to the probability of winning times the expected value of sitting in the Senate for the next period, plus the probability of losing times the value of exit (recall that a senator who loses a reelection bid then makes a post-congressional career decision), plus the term $\alpha_{R S}+\mu_{R S i t}$. Here, $\alpha_{R S}$ is the utility a senator gets from running for the Senate (which may be positive or negative, and whose sign is not obvious a priori), and $\mu_{R S i t}$ is the idiosyncratic component of the utility of running for reelection, which is specific to senator $i$ at time $t$. Finally, $X P_{i t}^{*}$ denotes the $X P_{i t}$ sub-vector of $X S_{i t}$ with $V E_{i t}$ set to 0 , since the senator exits via losing rather than voluntarily.

Decisions of representatives are more complex than those of senators, because representatives may have the option of running for the Senate. The choice set only includes this option if a Senate seat is up for election in the representative's State. Moreover, if a Senate seat is up for election, a representative's chances of winning the seat depend critically on the seat's incumbency status. If there is an incumbent senator of the representative's own party running for the seat, then there is (presumably) little chance he/she can win it. If there is an incumbent running

\footnotetext{
${ }^{19}$ The assumption that only "achievers" derive utility from accomplishments guarantees that $\alpha_{S}$ and $\alpha_{A S}$ are separately identified. Otherwise, identification would hinge subtly on variation of $p_{A S}$, the probability of achievement, with $X S_{i t}$.

${ }^{20} \mathrm{We}$ assume that $\mu_{1 S i t}$ is equal to the difference of two i.i.d type I extreme value error terms. This generates a logit form for the probabilities that the politician stays or exits (since the value of the exit option, $V_{E}\left(X P_{i, t+1}\right)$, has no error). Note also that $\mu_{I S i t}$ is a state variable relevant to the time $t$ decision, but, since it is serially independent, we follow convention and do enter it explicitly in our value function expressions.

${ }^{21}$ There are no important differences in the decisions of senators when $S T=1$ or $S T=2$.
} 
from the other party then the chances of winning may be better, but they are still likely to be small. If the seat is open, however, the representative's chances of winning may improve substantially.

Letting $X H_{i t}$ be the set of state variables relevant to the decisions of representatives, we have:

$$
\begin{aligned}
X H_{i t}=\left(X P_{i t}, S O D_{i}, S O S_{i t}, S O W_{t}, \text { Party }_{i}, \text { Achieve }_{i},\right. \\
\text { Scandal } \left._{i t}, \operatorname{Re} \text { dist }_{i t}, E S_{i t}, \text { Cycle }_{i t}, I N C_{i t}, \text { Cohort }_{i}\right)
\end{aligned}
$$

where $X P_{i t}$ denotes the vector of state variables relevant to post-congressional payoffs and the

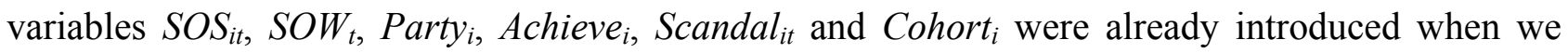
described the decisions of senators. Turning to the newly introduced state variables, note that a key aspect of a representative's decision problem is to forecast when Senate seats in his/her State will be up for election, and, if so, whether an incumbent will be running, as well as the incumbent's party affiliation. The problem is complicated by the fact that each State has two senators and it is uncertain when (and if) Senate seats will become open, because senators may die in office, leave the Senate before the end of their terms or decide not to run when their terms run out. ${ }^{23}$

To capture these aspects of the problem, we define new state variables that we call Cycle and INC. The position of a state in its "Senate cycle" refers to the number of periods until each of its two Senate seats comes up for election, baring unusual circumstance like death or early retirement of sitting senators. Cycle $=1,2,3$ indexes the three possible positions in the cycle, which are $(a, b)=(0,1),(0,2)$ or $(1,2)$ respectively, where $a$ is the number of periods until a Senate seat is first scheduled to come up, and $b$ is the number of periods until the next Senate seat is scheduled to come up. Cycle evolves deterministically. $I N C=1, \ldots, 4$ indexes the four possible states of incumbency for a State's two Senate seats, with the seats ordered by which is scheduled to come up for election first (as in the definition of Cycle). Letting $D$ and $R$ denote Democrat and Republican, respectively, the possibilities are $(D, D),(D, R),(R, D),(R, R)$. Thus, e.g., if $I N C=3$ we have $(R, D)$ which means the first seat has an incumbent Republican, while the next has an incumbent Democrat.

\footnotetext{
${ }^{22}$ Note that we do not model the outcome of primaries and general elections separately. If a senator or a representative loses a bid for reelection we do not distinguish if this was due to losing a primary or a general election.

${ }^{23}$ Clearly, a senator's decision to exit may depend on the identities of representatives who may run for his/her seat, as well as on decisions of other senators. Similarly, a representative's decision to run for Senate may depend on which other representatives from the same State are likely to do the same. Hence, the decisions of politicians may be viewed as outcomes of a dynamic game among the members of Congress. While certainly interesting, such an extension is clearly beyond the scope of our analysis. In this paper we abstract from all strategic considerations.
} 
The state variable $E S$ (“election status"), determines the set of options a representative faces. If $E S=1$ there is no Senate seat up for election in the representative's State, so his/her only options are to run for reelection or leave Congress. If $E S=2,3$ or 4 then there is a Senate seat up for election in the representative's State. There is an incumbent Democrat or Republican senator running for reelection as $E S=2$ or $E S=3$, respectively. If $E S=4$ the seat is open. $E S$ and $I N C$ evolve stochastically because of death and retirement by senators, and uncertainty about whether incumbent senators will run for reelection. ${ }^{24}$

Another state variable relevant to electoral prospects is $S O D_{i}$ ("state-of- the-district"), which measures whether a representative's district generally votes Republican or Democratic (See the Appendix for details). We define $S O D_{i}$ as a fixed characteristic of a district. Thus, we assume that $S O S$ and $S O W$ capture all time varying aspects of the electoral climate. For instance, a Democrat in a strongly Democratic district will normally have a high probability of reelection, but this probability is lower in years when the State and national political climate are favorable for Republicans. $^{25}$

Two other state variables that affect a representative's electoral prospects are whether his/her district has been affected by redistricting (in which case the dummy variable Redist $_{i t}$ takes the value 1 and zero otherwise) and whether the politician is currently involved in a scandal $\left(\right.$ Scandal $\left._{i t}\right)$.

The last variable in (10) is Cohort , which, as we noted when discussing senators, captures changes in congressional wages over time. Additionally, Cohort is important for representatives because, as is well known, House reelection probabilities have changed over time. A preliminary analysis of our data suggested clear breaks between the three entering cohorts we define.

The timing of events in the decision process for a representative is as follows. At the end of a two-year term, the representative decides whether to exit, run for reelection, or, if the option is available, run for Senate. At the time this decision is made, the politician knows the state of his/her district $(S O D)$, as well as $S O S, S O W$, Redist and Scandal for the upcoming election. All these variables affect his/her reelection chances. The representative also knows whether a Senate seat is

\footnotetext{
${ }^{24}$ We specify that the vector (INC, ES) evolves according to a Markov process with transition probabilities $P\left(I N C_{i, t+l}\right.$, $\left.E S_{i, t+1} \mid C y c l e_{i t}, I N C_{i t}, E S_{i t}\right)$. Note that $I N C$ and $E S$ could be predicted perfectly using lagged Cycle, INC and $E S$ if incumbent senators always ran for reelection, and never left office due to death, appointment to other offices or early retirement. Thus, these are the natural variables to use in predicting $I N C$ and $E S$. Of the 768 elements in this transition matrix, only 240 are feasible and, within this subset, only 56 are positive. We estimate these elements using empirical frequencies from the data, and then treat them as known in the solution and estimation of the model.
} 
up for election, whether an incumbent will run for the seat, and, if so, the party of that incumbent. If the politician decides to run for the House or Senate, he/she then gets a draw from a probability distribution that determines the election outcome. If the politician wins reelection to the House, he/she then gets draws from probability distributions that determine: (i) if he/she is made a member of a major committee, and (ii) if he/she has an important legislative accomplishment in that term. Then the process repeats itself. On the other hand, if the politician loses, or decides to leave Congress, he/she chooses an exit option, and the process terminates.

Consider a representative's decision when $E S=2,3$ or 4, so running for the Senate, running for reelection, or exiting Congress are all available options. The value of running for Senate is then:

$$
V_{R S}\left(X H_{i t}, h\right)=p_{H S}\left(X H_{i t}\right) E V_{S}\left(X S_{S}, s\right)+\left(1-p_{H S}\left(X H_{i t}\right)\right) V_{E}\left(X P_{i t}^{*}\right)+\left(\alpha_{H S}+\mu_{H S i t}\right)
$$

where $h$ indicates that the politician is sitting in the House. Equation (11) resembles (9), the value to a sitting senator of running for Senate, except that: (i) the probability of winning, $p_{H S}\left(X H_{i t}\right)$, is different (in particular, it also depends on whether an incumbent senator is running for the seat), and (ii) we allow the (mean) direct utility or disutility to a representative of running for a Senate seat, $\alpha_{H S}$, to differ from the utility or disutility that a sitting senator would receive.

On the other hand, the value of running for reelection to the House is:

$$
V_{R H}\left(X H_{i t}, h\right)=p_{H}\left(X H_{i t}\right) E V_{H}\left(X H_{i t}, h\right)+\left(1-p_{H}\left(X H_{i t}\right)\right) V_{E}\left(X P_{i t}^{*}\right)+\left(\alpha_{R H}+\mu_{R H i t}\right)
$$

where $p_{H}\left(X H_{i t}\right)$ is the probability of winning reelection to the House. The term $\alpha_{R H}$ is the value of the direct utility that the representative gets from running for the House (which may be positive or negative, and whose sign is not obvious a priori), while $\mu_{\text {RHit }}$ is the idiosyncratic component of the utility of running for reelection, which is specific to House member $i$ at time $t$.

The expected value of sitting in the House given reelection at time $t$ is:

$$
\begin{aligned}
E V_{H}\left(X H_{i t}, h\right)= & W_{H}(t)+\alpha_{H}+p_{C}\left(X H_{i t}^{*}\right) \alpha_{C}+\text { Achieve }_{i} p_{A H}\left(X H_{i t}\right) \alpha_{A H} \\
& +\delta\left(1-\pi_{d}(t)\right) E V\left(X H_{i, t+1}, h \mid X H_{i t}\right)
\end{aligned}
$$

The first four terms in (13) capture the current component of the payoff from sitting in the House at time t. $W_{H}(t)$ is the wage, and $\alpha_{H}$ is the monetized value of the utility of sitting in the House. The parameter $\alpha_{C}$ is the monetized value of the utility of being named to a major House committee, which is multiplied by the probability of being named, $p_{C}\left(X H_{i t}{ }^{*}\right)$, to get the expected utility. ${ }^{26}$

\footnotetext{
${ }^{25} S_{S O} S_{i t}$ and $S O W_{t}$ also influence the chances of winning a bid for higher office if a Senate seat is up for election. And, even with no Senate election at time $t, S O S_{i t}$ and $S O W_{t}$ help forecast the chance of winning a Senate bid in the future.

${ }^{26}$ Recall that in (3) we defined $X P_{i t}$ as including the House committee status state variable $C O M_{i t}$, which is therefore included in $X H_{i t}$. Hence, we let $X H_{i t}{ }^{*}$ denote the vector of state variables $X H_{i t}$, but with $C O M_{i t}$ replaced by $C O M_{i l-1}$.
} 
In addition, a representative of the type that values personal legislative achievements (i.e., Achieve $_{i}=1$ ) may also receive additional utility that is contingent on having an important legislative accomplishment in that period. We denote the probability of a political achievement by a representative by $p_{A H}\left(X H_{i t}\right)$, while $\alpha_{A H}$ is the monetized value of the utility increment generated by an achievement. Expected utility from legislative achievement is the product of these terms. ${ }^{27}$

The last term in (13) is the future component, which consists of the discount factor times the probability of survival to the next decision period, times the expected value of the state the representative will occupy at time $t+1$ when he/she next makes decisions about exiting Congress or running for office. This expectation is taken over several pieces of information, revealed after the representative is reelected at $t$, which affect the value of his/her options at time $t+1$. These are the realizations of: (i) selection to a major committee, (ii) variables that affect election prospects in the next election - SOS, SOW, Redist and Scandal, (iii) the status of the two Senate seats in his/her state at the time of the $t+1$ election, and (iv) the set of taste shocks at time $t+1 .^{28}$

\subsection{Probabilities of Winning, Committee Assignments and Legislative Achievements}

In Section 2.2, we introduced six functions that determine the probabilities of winning elections, important legislative achievements, and being named to a major House committee. We specify that each probability function $p_{S}\left(X S_{i t}\right), p_{H}\left(X H_{i t}\right), p_{H S}\left(X H_{i t}\right), p_{C}\left(X H_{i t}{ }^{*}\right), p_{A S}\left(X S_{i t}\right)$ and $p_{A H}\left(X H_{i t}\right)$ has a logistic form. The state variables that enter each of these logit probability functions are described in Table 1. The first column of the table lists all state variables in our model. In the subsequent columns, a check mark indicates a state variable is included in a particular probability function, a shaded area indicates it is not pertinent, and a blank space indicates it is intentionally excluded.

For example, in the third column, we describe the probability of winning reelection to the House, $p_{H}\left(X H_{i t}\right)$. This function includes age, terms in the House, major committee membership, whether the person is a skilled politician, cohort, party, redistricting and scandal, and the set of variables that describe the political climate for the election ( $S O D, S O S$ and $S O W)$. But of course it does not include $T S$ and $S T$, which are only relevant for senators, $V E$, which only matters after exit from Congress, or ES, Cycle, INC, which only affect opportunities to run for Senate. The potentially relevant variables that we chose to exclude are $B A, J D$, and Achieve. The first two were excluded

\footnotetext{
${ }^{27}$ The assumption that only "achievers" derive utility from accomplishments guarantees that $\alpha_{H}$ and $\alpha_{A H}$ are separately identified. Otherwise, identification would hinge subtly on variation of $p_{A H}$, the probability of achievement, with $X H_{i t}$.

${ }^{28}$ It is straightforward to work out the relevant value functions for a sitting representative's decision when $E S=1$, where the option of running for Senate is not available. They are therefore omitted.
} 
because preliminary analysis suggested they were unimportant. ${ }^{29}$ We exclude Achieve on theoretical grounds, since Skill captures unobservables related to ability to win elections. Recall that in our model there are four types, given by all possible combinations of Skill and Achieve. If "achievers" also tend to be "skilled," it will be captured by the "skilled achiever" type being relatively prevalent.

\subsection{Identification}

As we noted in the introduction, most existing studies that estimate election probability functions ignore the selection bias that arises because we only observe election outcomes for the selected sample of politicians who choose to run. Our model implements a selection correction to deal with this problem. That is, one can think of our model as generating a reduced form decision rule that politicians use to decide whether or not to run. This decision rule is analogous to the choice (or "observation") equation in simple static selection models, such as in Heckman (1979). As is well known (see, e.g., the discussion in Heckman and Honore (1990)), identification of selection models hinges crucially on exclusion restrictions or "instruments," by which we mean variables that enter the choice equation (i.e., the decision rule for running), but not the outcome equation (i.e., the probability of winning function). ${ }^{30}$ Our model generates a natural set of exclusion restrictions.

For instance, Table 1 shows all the variables that enter $p_{H}\left(X H_{i t}\right)$, the probability of reelection to the House. The excluded state variables, which affect decisions to run for reelection to the House, but that do not enter $p_{H}\left(X H_{i t}\right)$, include variables that: (i) influence the values of post-Congressional career options, and (ii) influence the opportunity to run for higher office. The former set of variables includes $B A$ and $J D$, which impact wages outside of Congress. It also includes the congressional pension. ${ }^{31}$ The latter set of variables includes $E S, C y c l e$, and $I N C$, which determine whether a Senate seat is up for election in the representative's State, as well as the incumbency

\footnotetext{
${ }^{29}$ Prior to estimation of the full model, we estimated reduced-form logits that contained all the pertinent state variables for each probability function, and conducted specification tests to determine which state variables could be dropped.

${ }^{30}$ Intuitively, the extent of selection bias is a decreasing function of the probability of running. Exclusion restrictions enable one to alter a variable, lets call it $X$, that enters the probability of winning function, while simultaneously altering an excluded variable, say $Z$, so as to hold the probability of running fixed. This identifies the effect of $X$ on the probability of winning, since, by holding the probability of running fixed, one holds the effect of selection fixed. Without exclusions, a selection model is identified purely from functional form and/or distributional assumptions.

${ }^{31}$ In (2) we wrote the pension as a function of $A g e$ and $T H$, which also enter the probability of winning reelection in the House. However, the pension rule has discontinuities at particular age and experience levels (see Appendix). These discontinuities affect decisions to run (while not affecting reelection probability), giving another source of identification.
} 
status of the seat. These variables only affect current and future chances of winning bids for higher office, but do not affect the probability of winning reelection in the House. ${ }^{32}$

Another issue concerns identification of how post-congressional wages depend on congressional experience. Of course, we also have exclusion restrictions here, because there are many variables in our model that affect decisions to exit Congress but that do not affect wages. Most obviously, these include $S O D, S O S$ and $S O W$, which influence reelection prospects. However, it is important to note that we can only identify how incremental terms in Congress affect postcongressional wages. Since our data set includes only members of Congress, we cannot identify the effect of a politician's first term in Congress on post-congressional wages (i.e., the effect of the first term is subsumed in the intercept of our wage functions). To identify the effect of the first term would be difficult, because one would need additional instruments that affect the probability of running for Congress in the first place, but that do not affect post-congressional wages.

Next, consider how the fraction of "achievers," $\pi_{A}$, and the probabilities of achievement, $p_{A H}$ and $p_{A S}$, are identified. For simplicity, consider only the House, and assume $\pi_{A}$ and $p_{A H}$ are constants that do not depend on state variables or covariates. Now, suppose that a fraction $\mu$ of representatives have an achievement each term. Further suppose that this same subset of representatives have achievements every term. It would then be clear that $p_{A H}=1$ and $\pi_{A}=\mu$. On the other hand, if there were no persistence of achievement within an individual history, we would estimate $p_{A H}=\mu$ and $\pi_{A}=1$. It is the extent of persistence of achievement within individual histories that determines how the estimates of $p_{A H}$ and $\pi_{A}$ fall between these two extremes. ${ }^{33}$

Finally, consider identification of the utility function parameters. Our model implies a structural decision rule for whether to run for reelection or higher office. This decision rule is a function of a set of non-pecuniary rewards, along with congressional wages, election probabilities and post-congressional earning opportunities. The political climate variables only affect these decisions via their effect on election probabilities, and the BA and JD variables only matter because

\footnotetext{
${ }^{32}$ Similarly, variables that influence the decision of a representative to run for the Senate, but that do not enter the Senate election probability function, include: (i) variables that influence the values of post-congressional career options, and (ii) variables that influence the value of running for reelection to the House. The latter includes SOD, the state of the local district, and COM, committee status. Finally, the variables that influence the decision of a senator to run for reelection to the Senate, but that do not enter the Senate election probability function, include only variables that influence the values of post-congressional career options, since senators do not have a third option in our model.

${ }^{33}$ The argument for identification of the fraction of skilled politicians is similar. If, conditional on observed state variables, election outcomes are iid when we look within politicians' histories over time, there would be no evidence that some politicians are more skilled at winning elections than others. But persistently "good" outcomes for a politician over time (relative to predicted outcomes based on observed state variables) imply that that the politician is "skilled."
} 
they effect outside earning opportunities. Thus, these two sets of variables provide instruments that identify the effect of election probabilities and outside opportunities on decisions to run for reelection or higher office.

Given that we can identify the monetary returns to congressional experience, probabilities of winning, and probabilities of achievements and committee assignments, as described earlier, and given that we can identify how reelection probabilities and outside earning opportunities affect decisions to run for reelection and higher office (as just described), the 13 utility function parameters that capture non-monetary rewards (from sitting in Congress, running for office, committee assignments, achievements, and post-congressional political jobs) are left as free parameters to help fit the wide array of conditional choice frequencies we observe in the data (i.e., the probabilities of running for reelection or higher office, conditional on a politician's history and the political climate, and the probabilities of choosing each of the three exit options, conditional on a politician's state at exit). Obviously, the utility function parameters are massively over-identified, since the number of conditional probabilities that the model attempts to fit is enormous.

\section{Data}

We construct a data set containing detailed information on careers of all House and Senate members who entered Congress from 1947 (the $80^{\text {th }}$ Congress) to 1993 (the $103^{\text {rd }}$ Congress). Our data end in 1994, so we have complete histories on members who left Congress in January 1995. But histories are right-censored for members who, in 1994, were reelected to serve in the $104^{\text {th }}$ Congress.

We define a career as uninterrupted service in Congress. A career is terminated the first time a member leaves Congress and either (i) chooses some other full-time occupation (either in the private or the public sector), (ii) retires from professional life, or (iii) dies. If a member has multiple spells or interrupted service - an event that occurs in less than 5\% of the cases - only the first spell is recorded. Individuals in our data set may serve only in the House; or in both the House and then the Senate (uninterrupted); or only in the Senate. Our final sample contains 1,899 career histories. $^{34}$

For each individual in our sample, the data set contains: (a) biographical data (i.e., age, place of birth, educational background, family background, party affiliation, prior political experience) and the record of congressional service; (b) a record of committee membership,

\footnotetext{
${ }^{34}$ Ambiguous entries (e.g., missing information on a person's middle name may prevent us from distinguishing members with the same first and last name) and observations with inconsistent or incomplete congressional records were dropped from the data. Members who serve in the Senate and then in the House - an extremely rare event - are also dropped.
} 
possible scandals while serving in Congress and congressional wages; (c) redistricting and congressional opportunities data (i.e., opportunities to run for a Senate seat, seat vacant or incumbent present, party affiliation of the incumbent); (d) a record of important legislative accomplishments (i.e., sponsoring major pieces of legislation, delivering famous speeches, casting decisive votes on important issues); (e) post-congressional data (i.e., type of first job after service, first annual salary, pension benefits). We describe the data in more detail, and discuss our data sources, in the Appendix.

Of the 1,899 people in our sample, $89 \%$ begin their congressional career in the House while $11 \%$ start in the Senate. 95 politicians die in office, and 413 are still in Congress at the end of our sample period. Of the 1,684 politicians who enter Congress in the House, 172 run for a Senate seat at some point in their career, and 58 succeed. During our sample period, there are 73 major scandals (66 involving a House member), 2,167 cases where a House member is affected by redistricting, ${ }^{35}$ and 270 important legislative accomplishments (133 by House members). As Democrats controlled the House throughout our sample period, they account for $56 \%$ of the sample. While $86 \%$ of the politicians in our sample have a bachelor's degree, nearly half (49\%) do not have a law degree.

We have post-congressional career information on 1,141 of the 1,391 members who exit Congress during our ample period. Of these, 52\% enter the private sector, $35 \%$ take another political job and 13\% retire. In 720 cases, we have information on their salary or pension. The average annual salary of former members of Congress in the private and public sectors (in 1995 dollars) are $\$ 252,583$ and $\$ 122,576$ (with standard deviations of $\$ 67,392$ and $\$ 43,319$ ), respectively.

There are five variables we use in estimation that we did not discuss in the model section. $H S E$ is a dummy equal to 1 if a member starts his/her career in the House, and, conversely Enter Senate is a dummy equal to 1 if the person starts in the Senate. Age at Entry indicates the member's age when they first enter Congress. Family is an indicator for whether an individual has relatives who had served in Congress, Home is an indicator for whether an individual serves in the same state where he/she was born, and Polexp is an indicator for whether an individual had political experience prior to entering Congress.

The variables Family, Home, Polexp, Enter Senate and Age at Entry are not state variables in our model. However, we use them, together with party affiliation, to help predict the

\footnotetext{
${ }^{35}$ Although most redistricting activity occurs after a Decennial census, some redistricting occurs every election year because of State Supreme Court rulings. Note that a single redistricting may affect many representatives.
} 
unobservable type of a politician. Specifically, we assume that the probability that $S k i l l_{i}=1$ and the probability that Achieve $_{i}=1$ are logistic functions of these six variables. This allows us, for example, to shed light on whether political experience prior to service in Congress, or coming from a "political family," are positively correlated with political skills, or whether a politician who enters the Senate directly or who is a member of a particular party is more likely to value legislative accomplishments.

A large fraction of the sample (68\%) serves in the same state where they are born, and a vast majority (78\%) held another local, state or federal office prior to service in Congress. Only a small fraction $(6 \%)$ had relatives elected to Congress before them. On average, a member of the U.S. Congress starts his or her congressional career at age 48 .

\section{Results}

In this section, we summarize our estimates and our main empirical findings, discussing each component of the model in turn. The maximum likelihood estimates (and standard errors) of the model parameters are reported in Table 2. For a detailed discussion of how we solve and estimate the model (including the likelihood function), see Diermeier, Keane and Merlo (2004).

\subsection{Probabilities of Winning, Committee Assignments and Legislative Achievements}

Several interesting results emerge from the estimated probabilities of winning House elections, winning Senate elections, and being named to a major House committee. Accumulated experience or seniority in the House (measured by the number of terms in the House), significantly affects the probability of winning reelection in the House, the probability of being named to a major House committee and the probability of winning a bid for a Senate seat. On the other hand, accumulated experience or seniority in the Senate (measured by the number of terms in the Senate), does not significantly affect the probability of winning reelection in the Senate. Holding everything else constant, age also has a significant effect on all these probabilities, indicating that general experience may also be a factor. Prior committee status (captured by the indicator variable $C O M_{t-1}$ ), is a strong predictor of the probability of being named to a major House committee, indicating a high degree of persistence in the composition of such committees (as is consistent with a seniority norm). Being a member of a major committee also increases the reelection probability in the House. Negative events, like scandals (either for a senator or a House representative) or redistricting (for a House representative), significantly reduce the probability of winning an election.

Unobserved heterogeneity in ability, captured by $S k i l l=0$ or 1 , plays an important role in determining politicians' electoral chances in both chambers of Congress. On average, our estimates 
imply that a House member who is a "skilled" politician (e.g., one with a valence or charisma advantage), has a $97.4 \%$ chance of winning a reelection bid in the House, compared to an $83.5 \%$ victory probability for a "normal" type. ${ }^{36}$ Similarly, a senator who is a skilled politician has, on average, an $87.6 \%$ chance of winning a reelection bid in the Senate, compared to only a $64.4 \%$ victory probability for a normal type. And a skilled politician in the House has, on average, a 24.4\% chance of winning a bid for the Senate, compared to only a $7.5 \%$ chance for a normal type.

The political climate variables enter the probability of winning functions in a very flexible way (see Table 2). To help interpret their impact, we present some examples. Consider a 48-yearold Democrat who is serving his/her first House term in the $100^{\text {th }}$ Congress, is not on a major committee, faces no scandal or redistricting, and is a normal type (i.e., Skill=0). Suppose $S O D$, $S O S$ and $S O W$, which we assume can take on values 1, 2 or 3, as the political climate is favorable for Republicans, neutral, or favorable for Democrats (see the Appendix), all equal 2, implying a neutral climate. Then, our estimates imply that the probability of winning a House reelection bid is $86.5 \%$. But, if $S O D, S O S$ and $S O W$ all equal 1, meaning the climate favors Republicans, this probability drops to only $42.5 \%$. While if $S O D, S O S$ and $S O W$ all equal 3, it increases to $99 \%$.

Now suppose an open Senate seat (i.e., no incumbent running) is up for election in this representative's State. Then, if $S O D, S O S$ and $S O W$ all equal 2 (i.e., the climate is neutral), his/her chance of winning a Senate bid is $14.8 \%$. If the three climate variables all favor Republicans, it falls to $9.5 \%$. Presence of an incumbent reduces the probability of a successful Senate bid even more. For instance, even if all the climate variables favor Democrats, the chance of a successful Senate bid against an incumbent Democratic senator is only $4.0 \%$.

As we have discussed, ignoring the fact that members of Congress may decide whether to run for reelection based, at least in part, on their probability of success, may lead to selection bias in estimates of reelection probabilities. But our model adjusts victory probability estimates by taking into account how members of Congress decide whether to run. To assess the impact of selection on observed victory probabilities, we simulate career histories from our model, and compare average victory probabilities between politicians who chose to run vs. those who do not run.

Our model implies that the average probabilty of winning reelection to the House among members who choose to run is $90.7 \%$, while the average victory probability among those who do

\footnotetext{
36 These figures are obtained by averaging over all states that occurred in the data. These are unconditional probabilities, in the sense that observations are included in the average regardless of whether the politician actually chose to run.
} 
not run is $88.1 \%$. Unconditionally, the victory probability is $90.4 \%$. These figures are open to different interpretations. Obviously, there is selection, in that victory probabilities are higher among House members who decide to run for reelection. On the other hand, the difference is modest, and the unconditional victory probability is nearly as high as the probability conditional on running. We conclude that very high House reelection probabilities are a real phenomenon, and not an artifact of selection. The pattern is similar in the Senate. Our model implies that the average victory probabilty among senators who choose to run for reelection is $81.8 \%$, while the average victory probability among those who choose not to run is $75.5 \%$. Unconditionally, the victory probability is $80.8 \%$.

Selection is much more quantitatively important for the probability of winning a bid for higher office. Our model implies that the average victory probabilty among House members who actually make a bid for a Senate seat is $36.6 \%$. But the unconditional probability of winning a bid for the Senate is only $16.3 \%$. This suggests that decisions of representatives about whether to run for higher office are quite sensitive to their chances of success.

Turning to the estimated probability of important legislative achievements by representatives and senators, we find that accumulated experience (i.e., seniority) increases the probability of a personal legislative achievement in both chambers. Committee membership, on the other hand, has no significant effect. Interestingly, Democrat representatives and senators are more likely to obtain important legislative accomplishments than Republicans. This may be because Democrats controlled both chambers of Congress during most of our sample period.

\subsection{Post-Congressional Wage Functions}

Our wage function estimates allow us to quantify the job-market returns to congressional experience, which is one of the primary goals of our research. Our findings indicate that congressional experience significantly increases wages in post-congressional occupations both in the private and in the public sector. However, the marginal effect of an additional term in Congress decreases rather rapidly with experience. Holding everything else constant, winning reelection in the House (Senate) for the first time increases post-congressional wages by $4.4 \%(16.7 \%)$ and $6.3 \%$ $(20.2 \%)$ in the private and public sectors, respectively. But averaging over members' actual experience levels, the marginal effect on post-congressional wages of an additional term in the House (Senate) is equal to $2.4 \%(5.2 \%)$ in the private sector and $2.6 \%(2.4 \%)$ in the public sector.

Several additional observations are noteworthy. All the other coefficients of the wage functions have reasonable signs and magnitudes. Interestingly, leaving Congress voluntarily is associated with lower wages in the private sector (but not in the public sector). As we alluded to 
earlier, this effect may arise because leaving Congress voluntarily indicates a politician's desire to "slow down," which would induce him/her to pursue lower paying but also less demanding jobs in the private sector. On the other hand, leaving as a "loser" may preclude a member of Congress from pursuing some other political offices.

An important finding is that a politician's unobserved skill-type has no effect on postcongressional wages either in the private or in the public sector. Politicians' unobserved attributes, such as valence or charisma, that, as illustrated above, play an important role throughout their congressional careers by increasing their probability of winning elections, do not seem to directly translate into better job-market opportunities outside of Congress. Thus, skilled politicians are not more productive in post-congressional employment. ${ }^{37}$

\subsection{Utility Function and Unobserved Heterogeneity}

The estimated utility function parameters imply that monetary rewards alone (i.e., congressional wages, and post-congressional payoffs) cannot explain the behavior of members of Congress. Politicians also care about non-pecuniary rewards. Our model enables us to place a monetary value on the non-pecuniary rewards from serving in Congress, and, to some extent, to decompose them by quantifying the benefits from important political accomplishments. We find that general nonpecuniary rewards amount to over $\$ 200,000$ per year for a senator and about $\$ 20,000$ to $\$ 35,000$ per year for a representative, depending on whether he/she is a member of a major House committee. Non-pecuniary rewards from achieving an important legislative accomplishment are comparable for representatives and senators and are both quite large (i.e., about $\$ 350,000$ and $\$ 400,000$, respectively). ${ }^{38}$ To provide a term of comparison, note that the average annual salary of a member of Congress in 1995 dollars over our sample period is equal to $\$ 120,378 .{ }^{39}$ We conclude that the non-pecuniary rewards from being in Congress are rather large (especially in the Senate) and that policy motivations may play an important role in the career decisions of some politicians. ${ }^{40}$

\footnotetext{
${ }^{37}$ The finding that unobserved heterogeneity in skills does not affect the wage functions does not imply that we could have estimated these functions separately from the rest of the model using OLS. There is still selection in terms of which post-congressional career option (private sector, public sector or retirement) is chosen. Variables like congressional experience, voluntary exit, education and committee status will be correlated with the error terms in the wage functions among the subsamples of politicians who select particular exit options, and are therefore endogenous.

${ }^{38}$ Legislative achievements as we have defined them are fairly rare. In our sample period we observe only about 11 on average per Congress. On the other hand, our estimates imply that only $27 \%$ of politicians are the type that cares about achievement. This implies that the probability of an achievement for a typical achiever is about $11 /(535 \times 0.27)=7.6 \%$ per term, implying an expected value of achievements of roughly $\$ 25,000$ to $\$ 30,000$ per term.

${ }^{39}$ To convert nominal amounts into real we used the CPI deflator and set 1995 as the base year.

${ }^{40}$ Furthermore, the estimated non-pecuniary reward from a post-congressional political job is about $\$ 90,000$ per year.
} 
Turning to politicians' unobserved heterogeneity, the estimated distribution of politician types implies that $46 \%$ are the "skilled" type while $27 \%$ are the "achiever" type. Regarding the joint distribution, $11 \%$ are skilled achievers, $35 \%$ are skilled only, $16 \%$ are achievers only, and $38 \%$ are neither. Interestingly, politicians who are younger when they first enter Congress, and politicians who enter the Senate directly, are more likely to be achievers. Political experience prior to entering Congress and being a Democrat are both negatively correlated with being an achiever (although neither effect is statistically significant). On the other hand, politicians who are older when they first enter Congress are more likely to be skilled. Being a skilled politician is also positively correlated with being a Democrat and having prior political experience (although neither correlation is statistically significant). ${ }^{41}$

\subsection{Goodness-of-Fit}

Our model specification is quite parsimonious, given the number of outcomes and behaviors that the model must fit (i.e., winning probabilities, committee appointments, political achievements, choice probabilities while in Congress, wages, occupational choices and retirement after exiting Congress). The only component of the model where we obviously have a great deal of leeway in terms of specification is in the utility function, but here we adopted a very simple specification with only 13 fundamental parameters. ${ }^{42}$ We would argue that this is extremely parsimonious, given the need to capture both decisions while in Congress ( 8 dedicated parameters) and post-congressional occupational choices (5 dedicated parameters).

To assess the overall fit of our model, we present Table 3 and Figures 1 and 2, which focus on different aspects of the data on congressional careers and post-congressional decisions, and compare the predictions of the model to their empirical counterparts. ${ }^{43}$ Overall the model tracks the behavior of politicians throughout their congressional careers remarkably well.

In the top panel of Table 3, we summarize the behavior of representatives for each possible "election status" as described by the state variable $E S$. Recall that $E S=1$ if no Senate seat is up for election in the representative's State. If $E S=2$ or 3 a Senate seat is up for election, but an incumbent Democratic or Republican senator is running for reelection. If $E S=4$ the Senate seat is open. The

\footnotetext{
${ }^{41}$ However, the estimated coefficients of each of the two type probability functions are jointly significant.

${ }^{42}$ Our logit functions for probabilities of winning and committee assignments have a large number of parameters, but the specifications of these functions are quite natural in light of the existing literature. Also, the specifications of the wage functions and the logit functions for probabilities of legislative accomplishments and type probabilities are very simple.

${ }^{43}$ The model predictions are based on 10,000 simulated individuals with the same distribution of initial conditions as in the data.
} 
model predicts representatives' choices in each case so accurately that, if we were to round to the nearest integer, the choice frequencies would be exact, with one exception. When there is an open Senate seat, the model predicts that $87 \%$ of representatives run for reelection to the House, while in the data only $85 \%$ run. To compensate, the model slightly under-predicts exit and the fraction of representatives who run for the Senate seat (each by $1 \%$ ).

As we can see from Table 3, the overwhelming majority of House members run for reelection, regardless of $E S$. Only a small fraction of representatives choose to give up their seat in the House to run for a seat in the Senate. But the percent who run for higher office is about four times larger when no incumbent senator is running for reelection.

In the middle panel of Table 3, we summarize the behavior of senators for each possible value of $S T$ ("Senate term"), which is equal to 1,2 or 3 as the senator has served 2, 4 or the full 6 years of his/her term, respectively. Again the predictions of the model are very accurate. The probability a senator runs for reelection is slightly overstated ( $85 \%$ vs. $84 \%$ in the data). Note that the fraction of senators who run for reelection is much smaller than that for representatives-but still very high.

In Figures 1 and 2, we plot the survival functions for members of the House and the Senate, respectively. As we can see for these figures, the model accurately predicts the observed career decisions of politicians through time in both chambers of Congress. ${ }^{44}$ Another interesting feature of the data is that the members of the House who choose to run for the Senate do so relatively early in their careers as representatives. If a representative does not run for the Senate by about his/her $5^{\text {th }}$ term, he/she is very unlikely to ever do so. The model accurately captures this pattern as well.

In the bottom panel of Table 3, we describe the fit to post-congressional career decisions. We distinguish between politicians who leave Congress voluntarily (i.e., $V E=1$ ) and those who are forced out via losing an election (i.e., $V E=0$ ), because their behavior is rather different. By and large, the model reproduces post-congressional career choices reasonably well, although not as well as it captures behavior while in Congress. We understate the fraction of voluntary leavers who enter the public sector $(31 \%$ vs. $35 \%$ in the data), and overstate the fraction who retire $(29.5 \%$ vs. $23.3 \%)$. And we understate the fraction of "losers" who enter the private sector $(55.5 \% \mathrm{vs} .61 .3 \%$ in the data), while overstating the fraction who enter the public sector $(39.6 \%$ vs. $35.1 \%)$. But the

\footnotetext{
${ }^{44}$ In the data, conditional on being elected to the House, the average number of terms a representative serves before exiting Congress is 4.9. The comparable figure for Senators is 1.9 terms. The average numbers of House and Senate terms predicted by the model are equal to 4.5 and 2.1 , respectively.
} 
model does generate the patterns that voluntary leavers are much more likely to retire than "losers," 45 and that voluntarily leavers are much less likely to enter the private sector. This is consistent with our finding that voluntarily leavers are offered lower private sector wages.

\section{The Value of a Seat in Congress}

In this section, we use our model to assess the value of a seat in Congress. Much of the recent literature on retirements from Congress has focused on monetary incentives, such as the option of converting unspent campaign funds to personal use (see Groseclose and Krehbiel (1994) and Groseclose and Milyo (1999)). Our model allows us to address the following more general question: What monetary payment (contingent on exit) would render a member of Congress ex ante indifferent between giving up his/her seat prior to the expiration of his/her current term and continuing his/her congressional career? Let Value ${ }_{i t}$ denote the answer to this question for politician $i$ at time $t$. We interpret this as the monetized value of a seat in Congress for a sitting member. Using our model, this value can be easily calculated and is equal to the ex ante difference between the value function of remaining in Congress and the value function of voluntarily exiting Congress. ${ }^{46}$ In particular, for a sitting House member we have:

$$
\text { Value }_{i t}=\left\{\begin{array}{ccr}
\bar{V}_{R H}\left(X H_{i t}, h\right)-V_{E}\left(X P_{i t}\right) & \text { if } & E S=1 \\
\max \left\{\bar{V}_{R H}\left(X H_{i t}, h\right), \bar{V}_{R S}\left(X H_{i t}, h\right)\right\}-V_{E}\left(X P_{i t}\right) & \text { if } & E S=2,3,4
\end{array}\right.
$$

while for a sitting member of the Senate we have:

$$
\text { Value }_{i t}=\left\{\begin{array}{llc}
\bar{V}_{S}\left(X S_{i t}, s\right)-V_{E}\left(X P_{i t}\right) & \text { if } & S T=1,2 \\
\bar{V}_{R S}\left(X S_{i t}, s\right)-V_{E}\left(X P_{i t}\right) & \text { if } & S T=3
\end{array}\right.
$$

The mean and standard deviation of the monetized value of a House seat in 1995 dollars computed using our estimated model are equal to $\$ 616,228$ and $\$ 170,415$, respectively. ${ }^{47}$ For a Senate seat, they are equal to $\$ 1,673,763$ and $\$ 344,302$, respectively. ${ }^{48}$

How does the value of a seat in Congress vary with individual characteristics? Table 4 reports OLS regressions of the log of the monetized value of a congressional seat, $\ln \left(\operatorname{Value}_{i t}\right)$, on

\footnotetext{
${ }^{45}$ The fraction of politicians who leave Congress voluntarily is $47.3 \%$, while the model predicts $43.3 \%$.

${ }^{46}$ Note that by ex ante we mean before the politician's taste shocks at the time of the decision to run for reelection are realized. If the ex-ante value functions are equalized, there is a 50/50 chance the politician will choose to exit after the taste shocks are realized. This ex ante indifference is identical to the criterion used in Groseclose and Milyo (1999).

${ }^{47}$ Like all other model predictions, these values are obtained by using the model to simulate 10,000 career histories.

${ }^{48}$ Note that our estimates do not correspond to what individuals who are not in Congress would be willing to pay to obtain a seat in Congress. In fact, our counterfactual experiment holds constant any accumulated congressional experience (and the present discounted value of all future returns it is expected to generate), and simply compares the ex ante values of continuing in Congress vs. that of exiting prior to the termination of a congressional term. To answer
} 
individual characteristics (i.e., BA, JD, Age, Skill, Achieve and Party), congressional experience, and the estimated probability of winning reelection, for members of the House and the Senate, respectively. Several interesting findings emerge from this table. As we would expect, ceteris paribus, individual characteristics that increase the outside opportunities of a member of Congress (like having a BA or a JD) lower the value of a seat in Congress. On the other hand, being a "skilled" politician (or an "achiever") increases the value of a House seat by $19 \%$ (13\%) and that of a Senate seat by $15 \%(16 \%)$. For a House member, being on a major committee increases the value of a House seat by $15 \%$. Holding everything else constant, a $1 \%$ increase in the probability of winning reelection in the House (Senate) translates into roughly a $0.6 \%(0.8 \%)$ increase in the value of a congressional seat. Interestingly, the value of a Senate seat is $4.8 \%$ higher for Democrats.

It is interesting to compare our estimates of the values of House and Senate seats to those obtained using alternative approaches, particularly Groseclose and Milyo (1999). As discussed by Groseclose and Krehbiel (1994), a 1979 amendment to the Federal Election Campaign Act prohibited members of the House from transferring unspent campaign funds to personal use after they left office. ${ }^{49}$ However, this amendment also contained a "golden parachute provision," which granted all House members elected prior to 1980 grandfather status. But a second amendment, passed into law in 1989, abolished this in 1992. Hence, in 1992, 158 members of the House were presented with a one-time choice between voluntarily exiting Congress and keeping their campaign war chests for personal use, or running for reelection and forever foregoing this opportunity.

While not directly comparable, this situation provides at least a benchmark to assess the outcome of our counterfactual experiment. In particular, from the politicians' decisions to forego specific amounts of money we can make some inference regarding properties of the distribution of the value of a House seat. Using the Groseclose and Krehbiel (1994) data, for the 158 members of the House who faced this decision, we computed descriptive statistics of the dollar amounts in their campaign war chest depending on whether they actually chose to rerun or exit Congress. The mean and standard deviation of these amounts (in 1995 CPI dollars) for the 33 members of the House who voluntarily exited Congress are $\$ 307,280$ and $\$ 235,028$, respectively. For the remaining 125 House members who decided to rerun, they are equal to $\$ 234,809$ and $\$ 232,711$, respectively.

the alternative question about value of entry, we would need to collect additional data on unsuccessful candidates and then model the initial decision to run for Congress. We intend to pursue this line of inquiry in future work.

${ }^{49}$ This amendment did not affect the members of the Senate since this option was never available to them. 
These two distributions overlap substantially, so there is obviously no clear threshold such that a member exited if and only if their "golden parachute" exceeded that value.

Using these data, Groseclose and Milyo (1999) estimate a model of the decisions of affected House members whether to run for reelection in 1992 vs. exit Congress. The amount in each member's campaign war chest provides an arguably exogenous source of variation in the value of the exit option, which helps to identify the model parameters. Groseclose and Milyo assume politicians' utility is a concave (CRRA) function of their wealth, and use imputed measures of the personal wealth of House members to estimate their utility from the convertible campaign cash. ${ }^{50}$ Their maximum likelihood estimates imply that the value of a House seat for a member of median age and median wealth is about three million dollars. However, the Groseclose and Milyo estimates are very sensitive to the coefficient of risk-aversion in the politicians' utility function, and the likelihood function of their model is very flat in this parameter. According to Groseclose (2002) their estimate of the value of a House seat falls to only about a quarter of a million dollars if they assume a linear utility function. Given the flatness of their likelihood surface, they cannot reject linear or nearly linear utility, so in fact their estimate does not strongly contradict ours. ${ }^{51}$

\section{Policy Experiments}

An appealing feature of our structural approach is that we can use the estimated model to evaluate the effects of various policy experiments on careers of politicians and the value of a congressional seat. Here, we analyze two experiments: an increase in the congressional wage and term limits.

Before we discuss these policy experiments, an important caveat is in order. Since our data only contain members of Congress, our analysis is limited to the study of politicians conditional on election to Congress. This implies that we cannot evaluate the impact of counterfactual experiments on the composition of the pool of potential candidates who choose to run for Congress in the first place. Our analysis of the effects of congressional wages and term limits is therefore only partial (i.e., it is conditional on election to Congress). Nevertheless, we believe it provides some new insights into the way such policies may affect the behavior of politicians.

\footnotetext{
${ }^{50}$ According to their data, the average wealth of a House representative in 1992 was $\$ 350,000$. Only about $5 \%$ had one million dollars or more, and less than $2 \%$ had more than five million dollars.

${ }^{51}$ A second important point is that the House members who were grand-fathered by the 1979 amendment to the Federal Election Campaign Act and were still serving in 1992 were not a random sample of the population of all members of Congress. This sample only includes those members with unspent campaign funds who were not defeated and chose not to exit Congress prior to 1992. Those House members who repeatedly rejected the option of leaving during the 19801990 period (during which they could have exited at any time and taken the campaign cash), are likely to be members who had relatively high values of remaining in Congress. Hence, any inference based solely on their observed behavior may not generalize to the overall population.
} 


\subsection{Congressional Wage Increase}

The first experiment we consider is a $20 \%$ increase in congressional wages (in real terms). Our main finding is that the effects of such a wage increase on the behavior of members of Congress are modest. Averaged over all relevant states, the probability a House member runs for reelection increases from $91.2 \%$ to $94.2 \%$, and the probability a senator runs increases from $85.2 \%$ to $87.1 \%$. ${ }^{52}$ For the members of the House, the probability of running for the Senate (conditional on a seat being up for election) decreases slightly from $3.0 \%$ to $1.9 \%$. Overall, the wage increase reduces early voluntary exit from Congress only by about $2 \%$, and has virtually no effect on the overall average duration of congressional careers or the post-congressional decisions of politicians. These effects are fairly similar across politicians with different (observable and unobservable) characteristics.

Turning our attention to the effects of an increase in the congressional wage on the value of a congressional seat, we find that a $20 \%$ wage increase increases the average value of a seat in the House by $22.9 \%$ and the average value of a seat in the Senate by $9.8 \% .^{53}$ This difference can be explained by the fact that, while the congressional wage is the predominant component of the perperiod expected payoff from serving in the House, it accounts for a much smaller portion of the perperiod expected payoff from serving in the Senate.

Recently, political economists have started to investigate the idea that paying politicians better may improve the average quality of politicians and their performance in office (see, e.g., Besley (2003)). Our analysis suggests that while a pay-raise clearly increases the value of holding office, the effects of congressional wages on the career decisions of sitting members of Congress are uniformly small, for all types of politicians.

\subsection{Term Limits}

In the second policy experiment, we consider a term limit regime where politicians can serve a maximum of four terms in the House and two terms in the Senate. This situation corresponds to an actual proposal that was considered in the early 1990s. In fact, between 1990 and 1994, many States approved initiatives to limit the number of terms served by their State legislators, and proposed to extend these limits to their members of Congress (see, e.g., Benjamin and Malbin (1992)). ${ }^{54}$

\footnotetext{
${ }^{52}$ All statistics reported in Section 6 are based on simulations of 10,000 career histories using our estimated model.

${ }^{53}$ Note that the effect of a $20 \%$ wage increase on the value of a seat can exceed $20 \%$ so long as the value of the outside alternative is positive. Effects of less than $20 \%$ will tend to arise if non-pecuniary returns are a large part of the value of a seat. The effect estimates we obtain are fairly homogeneous across politicians with different observed characteristics and unobserved types.

${ }^{54}$ These proposals range from imposing limits of as little as 3 to as many as 6 terms in the House. In our analysis, we experimented with all possible combinations. Qualitatively, the results were similar across all the different cases.
} 
Perhaps not surprisingly, we find that the presence of term limits substantially increases early voluntary exit both from the House and the Senate. ${ }^{55}$ Averaged over all relevant states, the probability a House member runs for reelection (to a $2^{\text {nd }}$ or $3^{\text {rd }}$ term) drops from $93.6 \%$ to $81.9 \%$, and the probability a senator runs for a $2^{\text {nd }}$ term drops from $87.0 \%$ to $77.1 \%$. For House members, imposition of term limits increases their probability of running for the Senate from $2.9 \%$ to $6.7 \%{ }^{56}$

A perhaps more interesting question, however, is whether term limits impact all individuals in the same way, or whether politicians with different characteristics are affected differently. We find that term limits have slightly larger impacts on the behavior of more skilled politicians, politicians who place more value on political achievements, and politicians who are older. These differences are more noticeable in the House, although we also find them in the Senate. On average, the imposition of term limits reduces the probability that a politician of normal type runs for reelection (to a $2^{\text {nd }}$ or $3^{\text {rd }}$ term) in the House by about $10 \%$. But for "skilled" politicians and "achievers" the declines are about 13\% and 12\%, respectively. Differences are also apparent by age. On average, the imposition of term limits reduces the probability that a relatively young politician (i.e., less than or equal to the mean age of 48 ) runs for reelection to a $2^{\text {nd }}$ or $3^{\text {rd }}$ term in the House by about $11 \%$. But for an older politician this probability goes down by about $13 \% .{ }^{57}$

Turning to the effects of term limits on the value of a congressional seat, we find that the imposition of term limits reduces the average value of a House seat by $39.8 \%$ and the average value of a Senate seat by $26.2 \%$. Consistent with our previous findings, the members of Congress who are most negatively affected by term limits are those who have better politicians' skills, value personal political achievements more, and are older. For example, while term limits reduce the value of a House (Senate) seat for a politician of normal type by about $37 \%(20 \%)$, the reductions for a "skilled" politician and an "achiever" are equal to about 42\% (29\%) and 41\% (27\%), respectively.

Many pro and con arguments for legislative term limits have been made (see, e.g., Benjamin and Malbin (1992) for a survey). Many have emphasized that, since reelection prospects create incentives for politicians to serve their constituents, imposing term limits may induce politicians to exercise less effort on behalf of their voters (see, e.g., Banks and Sundaram (1998) and Besley and Case (1995)). The results of our analysis suggest that another potential effect of term limits is that

\footnotetext{
${ }^{55}$ We compare the choices of House and Senate members under the two different scenarios prior to their $4^{\text {th }}$ House term and their $2^{\text {nd }}$ Senate term, respectively (when, under the term limit scenario, they would have to exit Congress).

${ }^{56}$ These findings are consistent with the observed behavior of state legislators following the introduction of term limits in the California state legislature in 1994 (see, e.g., Caress (1996)).

${ }^{57} \mathrm{We}$ find that the imposition of term limits has no significant effects on the post-congressional behavior of politicians.
} 
they may discourage relatively "skilled" politicians and politicians who are relatively more "policy minded" from staying in Congress. Our results also suggest that term limits might tend to tilt the composition of Congress toward younger and less experienced politicians.

\section{Conclusions}

In this paper, we have presented a novel approach to the empirical analysis of political careers based on the specification and estimation of a dynamic model of the career decisions of members of the U.S. Congress. Using a newly constructed data set that contains information on postcongressional employment, we have estimated the returns to congressional experience, quantified the value of a congressional seat, decomposed the overall returns to congressional service between monetary and non-pecuniary rewards, and related part of the non-pecuniary benefits from serving in Congress to data on important legislative achievements. By allowing for unobserved heterogeneity in the skills and motivations of politicians, we have estimated the frequency distribution of politicians' types, related the unobserved types to observable characteristics, and investigated the role of politicians' unobserved attributes in their congressional and post-congressional careers. We have also used our estimated model to assess the effects of an increase in the congressional wage and the imposition of term limits on the behavior of elected politicians.

While our analysis extends and generalizes most of the existing empirical literature on the study of political careers, there are several important issues we have neglected to address in this paper which represent possible directions for future research. One issue concerns the initial decisions of politicians to run for Congress, or more broadly, the decisions of people to become politicians. Progress on successfully addressing this question critically hinges on the collection of new data on the pool of potential candidates for public offices. Another important issue concerns the role of fundraising and campaigning in political careers. An extension of our model which incorporates these important aspects of politics could, for example, be used to address the interesting question of whether the intense fundraising and campaigning necessary to run for Congress serves as a deterrent to "public spirited" politicians, and tends toward an adverse selection of "political dealmakers" who are beholden to lobbyists and special interests. Such a model could also be used to assess the potential effects of various campaign finance reforms like the ones that have recently been proposed in the U.S. 


\section{REFERENCES}

Alesina, Alberto. 1988. "Credibility and Policy Convergence in a Two-Party System with Rational Voters." American Economic Review 78: 796-806.

Aragones, Enriqueta and Thomas Palfrey. 2002. "Mixed Equilibrium in a Downsian Model with a Favored Candidate." Journal of Economic Theory 103: 131-161.

Banks, Jeffrey S. and Rangarajan K. Sundaram. 1998. "Optimal Retention in Agency Problems.” Journal of Economic Theory 82: 293-323.

Bauer, M. and John R. Hibbing. 1989. "Why Incumbents Lose in House Elections: A Response to Jacobson's 'The Marginals Never Vanished'.” American Journal of Political Science 33: 262-271.

Benjamin, Gerald and Michael Malbin, eds. 1992. Limiting Legislative Terms. Washington, DC: Congressional Quarterly Press.

Besley, Timothy. 2003. "Paying Politicians: Theory and Evidence." Joseph Schumpeter Lecture at the $18^{\text {th }}$ Congress of the European Economic Association in Stockholm.

Besley, Timothy and Anne Case. 1995. "Does Electoral Accountability Affect Economic Policy Choices? Evidence from Gubernatorial Term Limits.” Quarterly Journal of Economics 110: 769-798.

Besley, Timothy and Stephen Coate. 1997. “An Economic Model of Representative Democracy.” Quarterly Journal of Economics 112: 85-114.

Caress, Stanley M. 1996. "The Impact of Term Limits on Legislative Behavior: An Examination of a Transitional Legislature.” Political Science and Politics 29: 671-676.

Deering, Christopher J. and Steven S. Smith. 1990. Committees in Congress. Washington, DC: Congressional Quarterly Press.

Diermeier, Daniel, Keane, Michael and Antonio Merlo. 2004. "A Political Economy Model of Congressional Careers.” Working paper, University of Pennsylvania.

Downs, Anthony. 1957. An Economic Theory of Democracy. New York: Harper Collins.

Eckstein, Zvi and Kenneth I. Wolpin. 1989. "The Specification and Estimation of Dynamic Stochastic Discrete Choice Models.” Journal of Human Resources 24: 562-598.

Groseclose, Timothy. 2001. "A Model of Candidate Location When One Candidate Has a Valence Advantage." American Journal of Political Science 45: 862-887.

Groseclose, Timothy, and Keith Krehbiel. 1994. "Golden Parachutes, Rubber Checks, and Strategic Retirements from the 102nd House." American Journal of Political Science 38: 75-99.

Groseclose, Timothy and Jeff Milyo. 1999. "Buying the Bums Out: What's the Dollar Value of a Seat in Congress?" mimeo. Graduate School of Business, Stanford University.

Groseclose, Timothy. 2002. Personal communication.

Hall, Richard L., and Robert van Houteling. 1995. "Avarice and Ambition in Congress: Representatives' Decisions to Run or Retire from the U.S. House”. American Political Science Review 89: 121-136.

Heckman, James J. 1979. “Sample Selection Bias as a Specification Error.” Econometrica 47: 153-162. 
Heckman, James and Bo Honore. 1990. "The Empirical Content of the Roy Model.” Econometrica 58: 11211150.

Hibbing, John R. 1991. Congressional Careers: Contours of Life in the U.S. House of Representatives. Chapel Hill, NC: University of North Carolina Press.

Jacobson, Gary. 1987. "The Marginals Never Vanished: Incumbency and Competition in Elections to the House of Representatives, 1952-1982.” American Journal of Political Science 31: 126-141.

Keane, Michael P. and Kenneth I. Wolpin. 1997. "The Career Decisions of Young Men.” Journal of Political Economy 105: 473-522.

Kiewiet, D. Roderick, and Langche Zeng. 1993. "An Analysis of Congressional Career Decisions, 19471986". American Political Science Review 87: 928-944.

Mayhew, David R. 1974a. Congress: The Electoral Connection. New Haven, Conn.: Yale University Press.

Mayhew, David R. 1974b. “Congressional Elections: The Case of the Vanishing Marginals.” Polity 6: 295317.

Mayhew, David R. 2000. America's Congress: Actions in the Public Sphere, James Madison Through Newt Gingrich. New Haven, Conn.: Yale University Press.

Mincer, Jacob. 1958. "Investment in Human Capital and Personal Income Distribution." Journal of Political Economy 66: 281-302.

Osborne, Martin J. and Al Slivinski. 1996. "A Model of Political Competition with Citizen-Candidates." Quarterly Journal of Economics 111: 65-96.

Rust, John. 1987. "Optimal Replacement of GMC Bus Engines: An Empirical Model of Harold Zurcher." Econometrica 55: 999-1033.

Rust, John. 1994. "Structural Estimation of Markov Decision Processes." In Handbook of Econometrics, vol. 4 edited by Robert F. Engle and Daniel L. McFadden, Amsterdam: North -Holland, Chapter 51, 3082-3139.

Sandefur, R. L. and E. O. Laumann. 1997. "Changing Patterns of Income Stratification in the Chicago Bar," mimeo, Northwestern University School of Law.

Schlesinger, Joseph. 1966. Ambition in Politics: Political Careers in the United States. Chicago: Rand McNally.

Sinclair, Barbara. 1989. The Transformation of the U.S. Senate. Baltimore: Johns Hopkins University Press.

Wittman, Donald. 1977. "Candidates with Policy Preferences: A Dynamic Model." Journal of Economic Theory 14: 180-189. 


\section{APPENDIX : Description of the Data}

For each individual in our sample, the data set contains the following information: (a) biographical data and record of congressional service; (b) record of committee membership, possible scandals while serving in Congress and congressional wages; (c) redistricting and congressional opportunities data; (d) record of important legislative accomplishments; (e) post-congressional data. We describe each part of the data set in turn.

(a) Biographical Data and Record of Congressional Service: The main building block of our data set is the Roster of U.S. Congressional Office Holders (1789-1993) (ICPSR \#7803) for the $80^{\text {th }}$ to $103^{\text {rd }}$ Congress. This data set contains 101 variables that provide information about the members' biographical characteristics, party affiliation and a complete record of their congressional service, including the reason why a member left Congress (e.g., because he/she was defeated in an election, retired, died in office, etc.). The official Biographical Directory of the U.S. Congress (1789-present) was used to check each relevant entry in our data set. $^{58}$ The Biographical Directory was also used to collect data on each member's age when entering Congress, whether they represented their state of birth, their educational background (i.e., whether they have a college degree and whether they have a law degree), whether they had relatives who had served in Congress, and whether they had political experience (i.e., they held another public office at the local, state, or federal level) prior to service in Congress.

(b) Committee, Scandal and Congressional Wage Data: The Kiewiet and Zeng (1993) data set was used to obtain information about committee assignments for the $80^{\text {th }}$ to $99^{\text {th }}$ House. Additional committee data for the $100^{\text {th }}$ to $103^{\text {rd }}$ House were collected using the relevant issues of the Congressional Quarterly Almanac. The Kiewiet and Zeng data set was also used to obtain information about scandals involving alleged sexual or financial misconduct by members of Congress for the $80^{\text {th }}$ to $99^{\text {th }}$ House. Additional data about the occurrence of scandals for the $100^{\text {th }}$ to $103^{\text {rd }}$ House and for all senators in our sample were collected using the same procedures and definitions used by Kiewiet and Zeng from the archives of the New York Times. Information on the annual salaries of the members of the U.S. Congress was obtained from the relevant issues of the Congressional Quarterly Almanac. ${ }^{59}$ All nominal wages were converted into 1995 CPI dollars.

(c) Redistricting and Congressional Opportunities Data: A data set assembled by Gary Jacobson was used to obtain information about all the occurrences of redistricting that affected any of the House members in our sample. Note that although most redistricting activity occurs after a Decennial census, many instances of redistricting occur every election year because of State Supreme Court rulings. Information on opportunities for House members to run for a Senate seat and on the identity and party affiliation of the incumbent (if present) was obtained from the Roster of U.S. Congressional Office Holders, supplemented by relevant issues of the Congressional Quarterly Almanac for elections to the $103^{\text {rd }}$ Senate.

(d) Legislative Achievements Data: The Mayhew (2000) data set contains detailed information about important legislative accomplishments by members of Congress (which Mayhew refers to as important "actions in the public sphere") from the $1^{\text {st }}$ through the $100^{\text {th }}$ Congress. ${ }^{60}$ These legislative achievements include the sponsoring of a major piece of legislation, the delivery of a famous speech, the casting of a decisive vote on an important policy issue etc. Using the same definitions and procedures used by Mayhew, we extended his data set to include important legislative achievements in the $101^{\text {th }}$ to $103^{\text {rd }}$ Congress based on the information reported in the relevant issues of the Congressional Quarterly Almanac.

(e) Post-Congressional Data: For most members of Congress, the official Biographical Directory of the U.S. Congress gives a short description of a member's professional life immediately after leaving congressional service, including the date of death if applicable. Based on the available descriptions we assigned all individuals who did not die in office and were not still in Congress at the end of our sampling period to one of the following categories: (i) private sector, (ii) public sector, or (iii) retired.

\footnotetext{
58 The directory is also available online at http://bioguide.congress.gov/biosearch/biosearch.asp.

${ }^{59}$ This information is also available online at http://www.congresslink.org/sources/salaries.html.

${ }^{60}$ According to Mayhew's (2000, pp. x-xi) definition “Actions' are, in principle, moves by members of Congress that are to a significant degree autonomous and consequential — or at least potentially consequential — and that are noticed by an alert stratum of the public exactly because of their perceived current or potential consequentiality."
} 
(i) Private Sector: The vast majority of former members of Congress who take jobs in the private sector work as lawyers, lobbyists, or political consultants. In these cases the description contained in the Biographical Directory is often sufficiently detailed to identify the specific law firm they join, or at least its location. To obtain estimates of the annual salaries of former members of Congress who choose these post-congressional occupations we relied on survey information. In particular, we used the wage function estimates based on a survey of Chicago lawyers conducted for the years 1975 and 1995 by Sandefur and Laumann (1997). For each of these two years, Sandefur and Laumann estimate a wage function for lawyers and lobbyists by regressing their log wages on biographical variables such as age, gender, ethnicity and father's occupation, as well as tenure, whether they attended an elite or prestigious law school, whether they were on their school's Law Review, size of their practice, field of practice and their position within the firm (e.g., whether they are partners or associates) ${ }^{61}$ To obtain information on all these variables for the relevant members of Congress in our sample we used the Biographical Directory, the Martindale-Hubbell archive and State Directories of Registered Professional Lobbyists. The Martindale-Hubbell archive provides detailed information about practicing lawyers in the U.S. including their address, field of practice, law school attended, year of admittance to bar, and membership of state bar associations. ${ }^{62}$ The Directories of Registered Professional Lobbyists contain similar information for licensed lobbyists in each state. ${ }^{63}$ Individuals that left Congress before 1985 were assigned estimates from the 1975 wage function; the others were assigned estimates from the 1995 wage function. Both estimates are in 1995 dollars. In addition, since only Chicago lawyers participated in the survey used by Sandefur and Laumann, the imputed wages for each of the relevant individuals in our sample were adjusted to account for the actual location of their practice. To make this adjustment we used data on billing rates for partners in law firms in different U.S. cities that we obtained from various issues of the Lawyer's Almanac. We then computed the ratios of average billing rates in each U.S. city relative to Chicago and multiplied the estimated wage for each individual by the appropriate coefficient depending of the location of their practice. ${ }^{64}$ It is important to note that although our procedure for imputing postcongressional wages in the private sector has limitations (for example, it is likely to understate the actual variation in wages), it nevertheless allows us to capture important features of the data. A key observation is that by and large, when former members of Congress work as lawyers or lobbyists, they are hired as partners of the firms they join (which entails a substantial wage premium over associates positions), in spite of the fact that their experience as lawyers or lobbyists would typically not justify their being offered these positions. In other words, individuals with a similar vector of characteristics (ignoring congressional experience) would not be partners in the data set used by Sandefur and Laumann. Thus, we expect that the effect of congressional experience on one's post-congressional wage (as a lawyer) will largely be captured by the effect of this experience on the chances of being made a partner. There are two other important related observations. First, the variance of wages of partners within law firms is rather small (which is due to the fact that partners share profits). Second, the variance of wages of partners across law firms is in large part explained by differences in location, size and field of practice (which are all factors we take into account in our imputation procedure, and which congressional experience presumably affects as well). The residual variation in wages, however, is clearly not zero, and hence the wage imputation procedure we use will in general understate the actual variation in wages.

(ii) Public Sector: To obtain the annual salary of individuals who served in a federal public office in the first year after leaving Congress we used the relevant sections of the United States Code for the years 1948-1995. For members who served in a state-level public office after leaving Congress we used the

\footnotetext{
${ }^{61}$ Law schools are coded as "elite" or "prestigious" according to whether they are ranked in the top-ten or top-twenty schools, respectively, in the U.S. News and World Report surveys. Also note that the data used by Sandefur and Laumann does not contain information on congressional experience.

${ }^{62}$ Recent editions of the archive are available online at http://www.martindale.com. For earlier years, printed editions of the archive were used. In some cases we used phone interviews to determine the year when an individual had joined a law firm and their position within the firm.

${ }^{63}$ Most of these directories are available online. Printed editions are also available for each state.

${ }^{64}$ If the location of the law practice was not known we used the billing rates for the closets city to the place of residence.
} 
relevant sections of the Book of the States for the years 1948-1995. Salary information about members who served in a county/city-level public office after leaving Congress was collected by directly contacting the relevant institution (e.g., the mayoral office). ${ }^{65}$

(iii) Retired: Information about pensions was collected using the relevant sections of the United States Code as well as the Federal Pensions Regulations for the years 1948-1995. These sources contain detailed information about eligibility requirements. For instance, annuities are paid only to members who are at least 62 years old and who have completed at least six years of service, members who are at least 60 years old and who have completed at least ten years of service, and members who are at least 50 years old and who have completed at least twenty years of service. In all these cases, members have to be separated from the service to be eligible for benefits. Annuities are equal to $2.5 \%$ of a member's average annual salary while in Congress for each year of service, up to $80 \%$ of his or her salary prior to exiting Congress.

Finally, to construct the $S O D, S O S$ and $S O W$ variables we used the Brady and Rivers (unpublished) electoral data set (1952-1996), which is based on the relevant issues of the Congressional Quarterly Guide to U.S. Elections as well as the America Votes series. The procedures we used to construct these variables are as follows. We classify the overall state of the world $(S O W)$ to be good, neutral, or bad for the election of Democrats based on the overall vote in all congressional elections to the House of Representatives. ${ }^{66}$ Define the normalized Democratic national vote share as $D(n) /[D(n)+R(n)]$, where $D(n)$ is the total vote for Democrats in House elections nationally, and $R(n)$ is the total vote for Republicans. If the normalized national vote share is more than $58 \%$ Democratic, we classify $S O W$ as good for Democrats $(S O W=3)$. If the vote share is in the $55-58 \%$ range we classify $S O W$ as neutral $(S O W=2)$, and if the vote share is less than $55 \%$ Democratic we classify $S O W$ as relatively good for Republicans $(S O W=1)$. The bias in these figures reflects the fact that Democrats received the majority of the national vote in House elections in all years of our sample period. These cut off points generate a distribution where each value of SOW occurs roughly a third of the time. Next, we construct $S O S$ to be a measure of the state of a state relative to the national political climate. Define $D(s) /[D(s)+R(s)]$ as the normalized vote share for the Democrat in the presidential election in state $\mathrm{s}$ in a particular year. Comparing the state level vote share to the national presidential vote share, $S O S$ is classified as good for the Democrats $(S O S=3)$ if the difference in vote shares is greater than $4 \%$. $S O S$ is classified as neutral $(S O S=2)$ if the difference is between $4 \%$ and $-4 \%$, and $S O S$ is classified as bad for Democrats $(S O S=1)$ if the difference is less than $-4 .{ }^{67}$ These cutoffs again generate a distribution with roughly a third of observations in each range. Finally, to construct $S O D$, which is a (constant over time) measure of the typical political climate in a district, we first construct the intermediate variable $A S O D$ using the same procedure we used to construct $S O S$, except that it is based on the district level presidential vote relative to the national vote. Next, to convert this to a constant over time measure, we use the following procedure: For each representative $i$ we compute the average difference between $S O S_{i t}$ and $A S O D_{i t}$ over his/her career horizon and we classify a district as good for Democrats relative to the State the district belongs to $(S O D=3)$ if the average difference is greater than 0.25 , as bad $(S O D=1)$ if it less than -0.25 , and as neutral $(S O D=2)$ otherwise. These cutoffs again generate a distribution with roughly a third of observations in each range. Finally, note that although we assume that the state of the district a representative is in remains constant over his/her time horizon, the state of a district is allowed to change as the identity of the representative of that district changes.

\footnotetext{
${ }^{65}$ All nominal figures were converted into 1995 dollars using the CPI deflator.

${ }^{66}$ We use the overall House vote rather than the presidential vote for two reasons. First, the presidential vote occurs only every four years. Second, the presidential vote may be dominated by the particular personalities of the presidential candidates, and not accurately reflected circumstances in local elections. In contrast, the cumulative House vote should not be dominated by individual personalities.

${ }^{67}$ Here we use the presidential vote rather than the state-wide House shares because state-wide House vote shares may be dominated by local personalities, especially in states with only a few congressional districts. We hope the influence of the personalities of particular presidential candidates cancel out when we take the difference in state vs. national presidential votes.
} 
Table 1: Specification of Probability Functions

\begin{tabular}{|c|c|c|c|c|c|c|}
\hline State Variable & $p_{S}\left(X S_{i t}\right)$ & $p_{H}\left(X H_{i t}\right)$ & $p_{H S}\left(X H_{i t}\right)$ & $p_{C}\left(X H_{i t}{ }^{*}\right)$ & $p_{A S}\left(X S_{i t}\right)$ & $p_{A H}\left(X H_{i t}\right)$ \\
\hline \multicolumn{7}{|l|}{$B A_{i}$} \\
\hline \multicolumn{7}{|l|}{$J D_{i}$} \\
\hline$A g e_{i t}$ & $\sqrt{ }$ & $\sqrt{ }$ & $\sqrt{ }$ & $\sqrt{ }$ & & \\
\hline$T H_{i t}$ & & $\sqrt{ }$ & $\sqrt{ }$ & $\sqrt{ }$ & & $\sqrt{ }$ \\
\hline$T S_{i t}$ & $\sqrt{ }$ & & & & $\sqrt{ }$ & \\
\hline$C O M_{i t}\left(C O M_{i t-1}\right)^{*}$ & & $\sqrt{ }$ & & $\sqrt{ }^{*}$ & & $\sqrt{ }$ \\
\hline \multicolumn{7}{|l|}{$V E_{i t}$} \\
\hline Party $_{i}$ & $\sqrt{ }$ & $\sqrt{ }$ & $\sqrt{ }$ & $\sqrt{ }$ & $\sqrt{ }$ & $\sqrt{ }$ \\
\hline Skill $_{i}$ & $\sqrt{ }$ & $\sqrt{ }$ & $\sqrt{ }$ & $\sqrt{ }$ & & \\
\hline Achieve $_{i}$ & & & & & $\sqrt{ }$ & $\sqrt{ }$ \\
\hline$S O D_{i}$ & & $\sqrt{ }$ & & $\sqrt{ }$ & & \\
\hline$S O S_{i t}$ & $\sqrt{ }$ & $\sqrt{ }$ & $\sqrt{ }$ & $\sqrt{ }$ & & \\
\hline$S O W_{t}$ & $\sqrt{ }$ & $\sqrt{ }$ & $\sqrt{ }$ & $\sqrt{ }$ & & \\
\hline Scandal $_{i t}$ & $\sqrt{ }$ & $\sqrt{ }$ & $\sqrt{ }$ & & & \\
\hline Redist $_{i t}$ & & $\sqrt{ }$ & & & & \\
\hline$S T_{i t}$ & $\sqrt{ }$ & & & & & \\
\hline$E S_{i t}$ & & & $\sqrt{ }$ & & & \\
\hline Cycle $_{i t}$ & & & $\sqrt{ }$ & & & \\
\hline$I N C_{i t}$ & & & $\sqrt{ }$ & & & \\
\hline Cohort $_{i}$ & & $\sqrt{ }$ & & & & \\
\hline
\end{tabular}




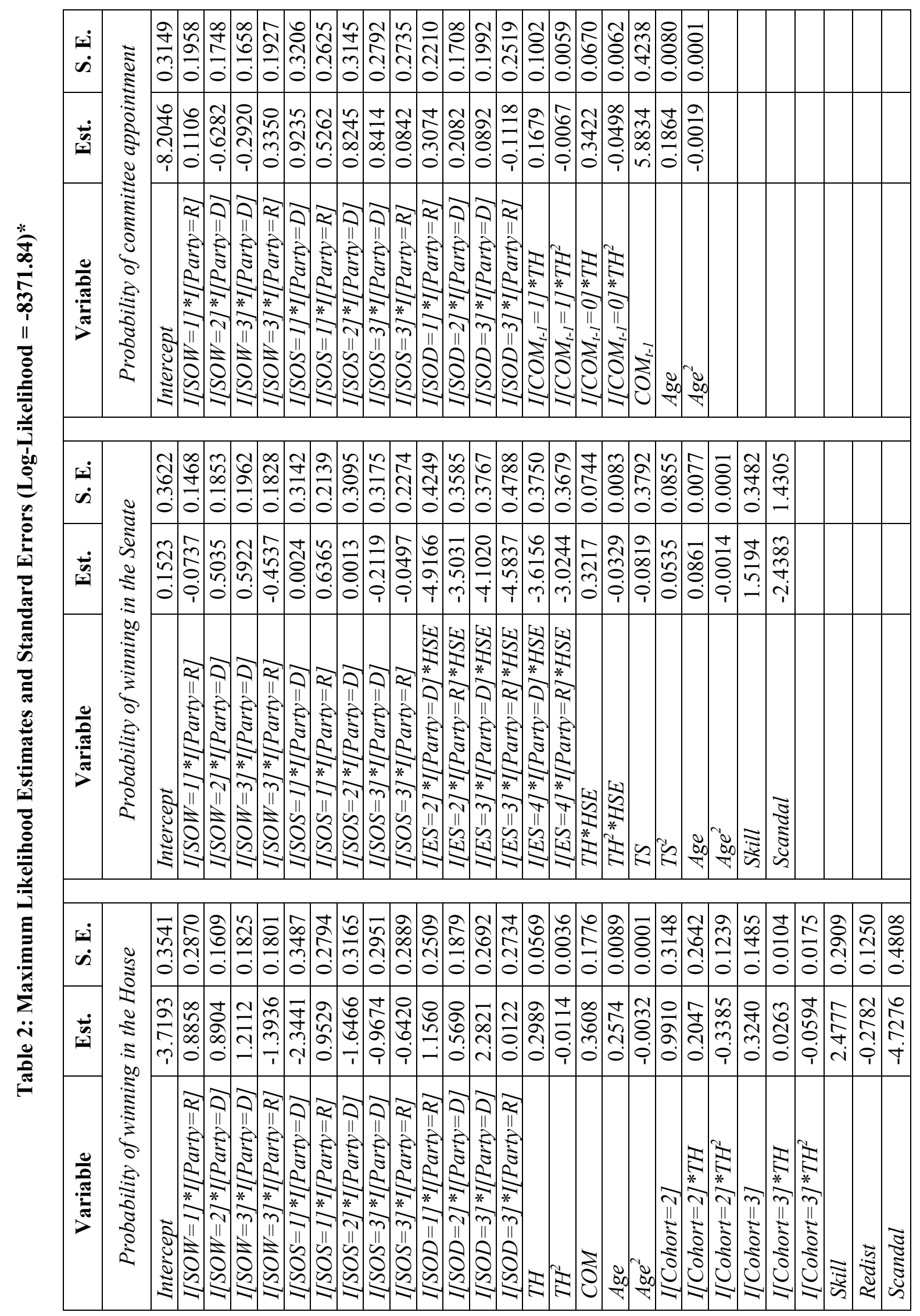




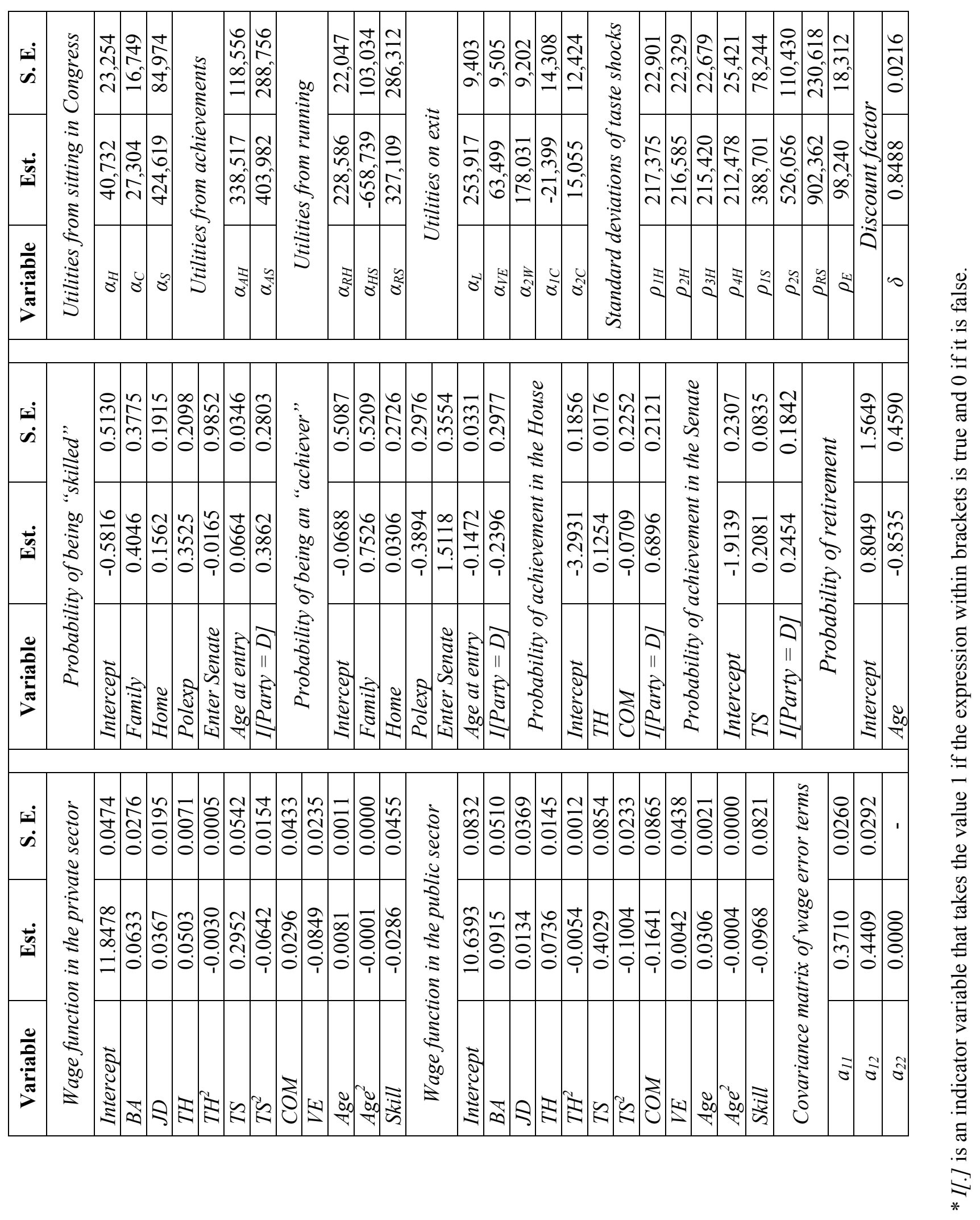


Table 3: Decisions of Members of Congress

\begin{tabular}{|c|c|c|}
\hline & Data & Model \\
\hline \multicolumn{3}{|c|}{ Decisions of Representatives } \\
\hline \multicolumn{3}{|c|}{$E S=1$} \\
\hline$\%$ rerun for House & 93.15 & 92.99 \\
\hline$\%$ exit Congress & 6.85 & 7.01 \\
\hline \multicolumn{3}{|c|}{$E S=2$} \\
\hline$\%$ rerun for House & 91.06 & 90.84 \\
\hline$\%$ run for Senate & 2.15 & 2.25 \\
\hline$\%$ exit Congress & 6.79 & 6.91 \\
\hline \multicolumn{3}{|c|}{$E S=3$} \\
\hline$\%$ rerun for House & 91.12 & 91.23 \\
\hline \% run for Senate & 2.34 & 2.30 \\
\hline$\%$ exit Congress & 6.54 & 6.47 \\
\hline \multicolumn{3}{|c|}{$E S=4$} \\
\hline$\%$ rerun for House & 84.76 & 86.77 \\
\hline$\%$ run for Senate & 8.42 & 7.44 \\
\hline$\%$ exit Congress & 6.82 & 5.79 \\
\hline \multicolumn{3}{|c|}{ Decisions of Senators } \\
\hline \multicolumn{3}{|c|}{$S T=1$} \\
\hline$\%$ stay in Senate & 98.17 & 97.96 \\
\hline$\%$ exit Congress & 1.83 & 2.04 \\
\hline \multicolumn{3}{|c|}{$S T=2$} \\
\hline$\%$ stay in Senate & 95.34 & 95.38 \\
\hline$\%$ exit Congress & 4.66 & 4.62 \\
\hline \multicolumn{3}{|c|}{$S T=3$} \\
\hline$\%$ rerun for Senate & 83.85 & 85.24 \\
\hline$\%$ exit Congress & 16.15 & 14.76 \\
\hline \multicolumn{3}{|c|}{ Post-Congressional Career Decisions } \\
\hline \multicolumn{3}{|c|}{$V E=1$} \\
\hline$\%$ private sector & 41.61 & 39.63 \\
\hline$\%$ public sector & 35.00 & 30.86 \\
\hline$\%$ retire & 23.39 & 29.51 \\
\hline \multicolumn{3}{|c|}{$V E=0$} \\
\hline$\%$ private sector & 61.27 & 55.53 \\
\hline$\%$ public sector & 35.11 & 39.63 \\
\hline$\%$ retire & 3.61 & 4.83 \\
\hline
\end{tabular}


Table 4: OLS Regressions of log Value of a Congressional Seat

\begin{tabular}{|c|c|c|}
\hline Variable & Coefficient & S. E. \\
\hline \multicolumn{3}{|c|}{ Value of a House Seat } \\
\hline Intercept & 12.5797 & 0.0151 \\
\hline$B A$ & -0.0791 & 0.0016 \\
\hline$J D$ & -0.0334 & 0.0012 \\
\hline Age & 0.0240 & 0.0006 \\
\hline$A g e^{2}$ & -0.0003 & 0.0000 \\
\hline TH & -0.0569 & 0.0005 \\
\hline$T H^{2}$ & 0.0002 & 0.0000 \\
\hline COM & 0.1530 & 0.0015 \\
\hline Skill & 0.1893 & 0.0013 \\
\hline Achieve & 0.1312 & 0.0013 \\
\hline$I[$ Party $=D]$ & -0.0027 & 0.0011 \\
\hline$p_{H}$ & 0.6474 & 0.0042 \\
\hline \multicolumn{3}{|l|}{$R^{2}=0.8836$} \\
\hline \multicolumn{3}{|c|}{ Value of a Senate Seat } \\
\hline Intercept & 12.1649 & 0.0576 \\
\hline$B A$ & -0.0384 & 0.0054 \\
\hline$J D$ & -0.0162 & 0.0036 \\
\hline Age & 0.0679 & 0.0021 \\
\hline $\mathrm{Age}^{2}$ & -0.0007 & 0.0000 \\
\hline$T H$ & -0.0494 & 0.0032 \\
\hline$T H^{2}$ & 0.0029 & 0.0006 \\
\hline$T S$ & -0.0925 & 0.0058 \\
\hline$T S^{2}$ & 0.0129 & 0.0011 \\
\hline Skill & 0.1520 & 0.0063 \\
\hline Achieve & 0.1608 & 0.0034 \\
\hline$I[$ Party $=D]$ & 0.0476 & 0.0035 \\
\hline$p_{S}$ & 0.8045 & 0.0243 \\
\hline$R^{2}=0.9210$ & & \\
\hline
\end{tabular}


Figure 1: Survival Function for House

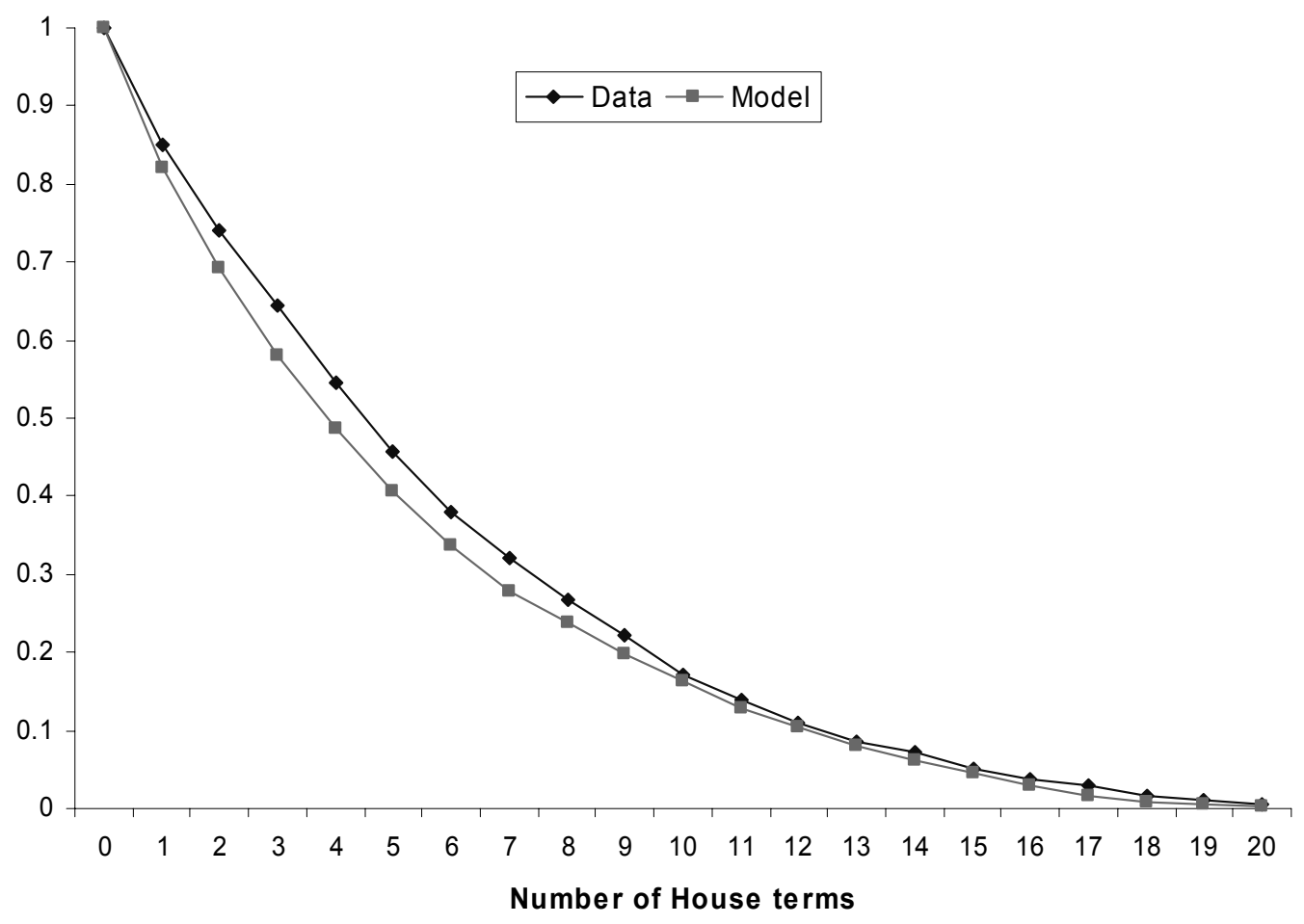

Figure 2: Survival Function for Senate

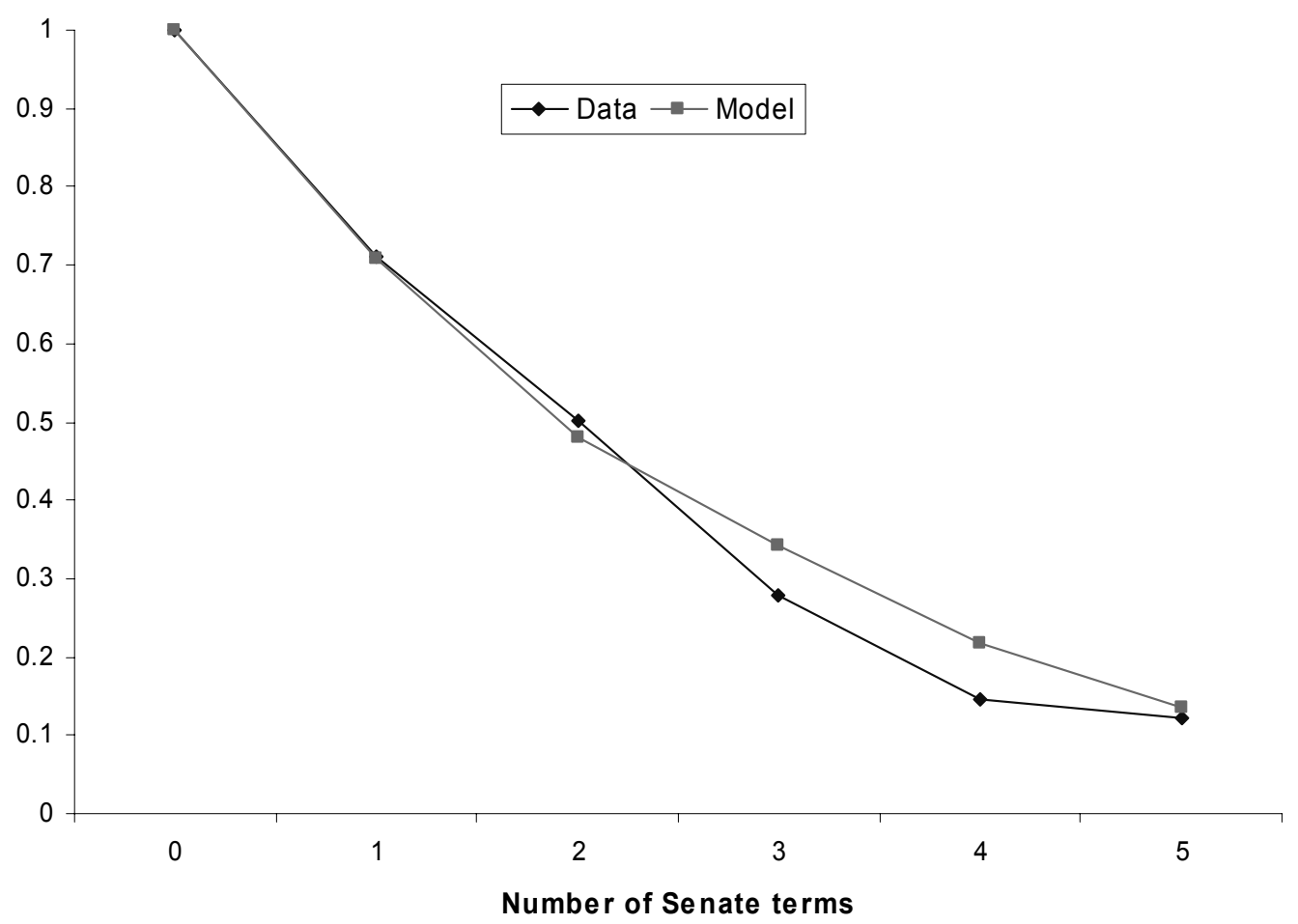

